\title{
Cyanophycin and arginine metabolism in cyanobacteria
}

\author{
Enrique Flores $^{1 *}$, Sergio Arévalo ${ }^{1}$ and Mireia Burnat ${ }^{2}$
}

${ }^{I}$ Instituto de Bioquímica Vegetal y Fotosíntesis, CSIC and Universidad de Sevilla, Américo Vespucio 49, E-41012 Seville, Spain

${ }^{2}$ Department of Marine Biology and Oceanography, Institut de Ciències del Mar, CSIC, Passeig Marítim de la Barceloneta 37-49, E-08003 Barcelona, Spain

*For correspondence, e-mail address: eflores @ibvf.csic.es.

Keywords: Anabaena; Nostoc; Nitrogen metabolism; Nitrogen mobilization; Nitrogen storage; Synechocystis.

\begin{abstract}
Cyanobacteria are oxygenic phoautotrophs that can utilize inorganic nitrogen salts, atmospheric nitrogen and some amino acids such as arginine as nitrogen source. Under unbalanced growth in the presence of sufficient nitrogen, many cyanobacteria accumulate cyanophycin, a co-polymer of aspartate and arginine that serves as a nitrogen reservoir. Cyanophycin metabolism enzymes include cyanophycin synthetases, cyanophycinase and isoaspartyl dipeptidase, which splits $\beta$ aspartyl arginine released from cyanophycin by cyanophycinase into aspartate and arginine. The arginine catabolic pathway of cyanobacteria has been recently elucidated and consists of two bifunctional enzymes, arginine-guanidine removing enzyme (AgrE) and proline oxidase (PutA). This pathway makes available to metabolism the four nitrogen atoms of arginine, three as ammonia and one as glutamate. A variant of the pathway cycles ornithine (an intermediate in the AgrE-catalyzed reactions) back to arginine incorporating aspartate and, hence, recovering its nitrogen atom for metabolism. Many cyanobacteria also make use of this pathway to utilize arginine taken up from the outer medium through a high-affinity $\mathrm{ABC}$ transporter. An analysis of co-occurrence in cyanobacteria of the genes encoding enzymes of cyanophycin metabolism, arginine catabolism and the arginine and aspartate transporters indicates a strong correlation between the presence of cyanophycin and the AgrE/PutA pathway.
\end{abstract}




\section{Introduction}

Cyanobacteria are a phylogenetically coherent group of bacteria that have the capability to carry out oxygenic photosynthesis [1]. $\mathrm{CO}_{2}$ fixation is carried out in carboxysomes that are cell inclusions in which carbonic anhydrase and ribulose-1,5-bisphosphate carboxylase/oxygenase (RuBisCo) are encapsulated in a shell composed of specific proteins [2]. Cyanobacteria can grow photoautotrophically using preferentially ammonium, nitrate or urea as nitrogen source, but many cyanobacteria can fix atmospheric $\mathrm{N}_{2}$ and, hence, they can grow with air and water containing a few essential mineral salts [3, 4]. Nonetheless, many cyanobacteria are also able to take up some sugars as carbon and energy sources and some amino acids as nitrogen sources [5], which increases the trophic modes of these organisms including mixotrophy -the ability to use simultaneously several redundant growth resources. In spite of a unifying capability for photoautotrophic growth, the cyanobacteria show a remarkable morphological diversity [1]. There are unicellular and multicellular cyanobacteria, and many of the latter can produce differentiated cells specialized for specific functions $[6,7]$. The cyanobacteria can also be classified according to the carboxysomes they bear, $\alpha$ or $\beta$ carboxysomes, which are made of phylogenetically distinct protein components [2, 8]. Notably, whereas most cyanobacteria contain $\beta$ carboxysomes, the marine unicellular Synechococcus and Prochlorococcus strains contain $\alpha$ carboxysomes [8].

The enzyme that carries out $\mathrm{N}_{2}$ fixation, nitrogenase, is extremely sensitive to $\mathrm{O}_{2}$ posing an especial problem for $\mathrm{N}_{2}$ fixation in the oxygenic cyanobacteria [9]. Some cyanobacteria such as the marine filamentous organism Trichodesmium erythraeum can carry out $\mathrm{N}_{2}$ fixation in vegetative cells in the light with a possible uncoupling from $\mathrm{CO}_{2}$ fixation $[10,11]$, whereas many other cyanobacteria manifestly separate $\mathrm{N}_{2}$ fixation from photosynthesis. Thus, some unicellular cyanobacteria restrict $\mathrm{N}_{2}$ fixation to the dark period of diel cycles [12] and some filamentous cyanobacteria restrict $\mathrm{N}_{2}$ fixation to specialized micro-oxic cells in the filament [6]. This is the case of cyanobacteria that produce cells specialized for $\mathrm{N}_{2}$ fixation termed heterocysts, which represent $10 \%$ of the cells of the filament, do not perform oxygenic photosynthesis and rely on reduced carbon received from the adjacent vegetative cells [13]. In turn, the heterocysts provide the vegetative cells with fixed nitrogen in the form of amino acids [13]. Under conditions of nitrogen deprivation, some vegetative cells in the filament differentiate into heterocysts in a process that involves a specific program of gene expression [14]. Importantly, heterocystous cyanobacteria are a monophyletic group of organisms [15], implying that the heterocyst evolved only once, likely over 2,100 million years ago [16]. The heterocystous cyanobacteria for which more physiological and molecular data are available belong to the genera Anabaena and Nostoc (order Nostocales [1]). 
A type of cell inclusion present in many cyanobacteria is the cyanophycin granules, which are composed of a material known as cyanophycin granule polypeptide or, simply, cyanophycin. Discovered in, and once thought to be characteristic of cyanobacteria, cyanophycin is now known to be produced by some other bacteria as well [17]. Cyanophycin is a non-ribosomally synthesized polypeptide that consists of a poly- $\alpha$-aspartic acid peptidic backbone with arginine linked via isopeptide bonds to the $\beta$-carboxyl group of each aspartic acid in the backbone (multi-L-arginylpoly [L-aspartic acid]) $[18,19]$. Cyanophycin is a carbon and nitrogen storage polymer that, given its relatively high $\mathrm{N}$ to $\mathrm{C}$ ratio, can be considered a nitrogen reserve. Excellent reviews covering different aspects of cyanophycin biology are available [17, 20,21]. Here we shall address the biosynthesis and degradation of cyanophycin and the metabolism of its constituent amino acids in cyanobacteria. We shall also address the capability of cyanobacteria to take up arginine and aspartate from the external medium, as well as a possible correlation between production of cyanophycin and presence of specific arginine utilization pathways.

Two model strains for which much information is available are the unicellular cyanobacterium Synechocystis sp. PCC 6803 and the heterocystous cyanobacterium Anabaena (also known as Nostoc) sp. PCC 7120, which in this article will be referred to as Synechocystis and Anabaena, respectively. Along the text, we shall identify proteins from these organisms that are related to the topic of this review.

\section{Cyanophycin synthesis and degradation}

\subsection{Genes and enzymes}

The cyanophycin granule found in cyanobacteria is an insoluble material that is frequently 25 to $100 \mathrm{kDa}$ in size. As first shown by studies in Synechocystis, cyanophycin peptide is elongated by cyanophycin synthetase, the product of the $c p h A$ gene [22], and degraded by cyanophycinase, the product of the $c p h B$ gene [23]. Cyanophycin synthetase first adds aspartate to the poly- $\alpha$-aspartic acid backbone and then adds arginine to the $\beta$-carboxyl group of the incorporated aspartate (Fig. 1A). Each of these reactions consume one ATP molecule and is carried out in an independent reaction center in cyanophycin synthetase, which are localized at the $\mathrm{N}$-terminal and $\mathrm{C}$-terminal parts of the enzyme, respectively [24]. Cyanophycinase is a serine-type peptidase that degrades cyanophycin by removing $\beta$-aspartyl-arginine dipeptide sequentially $[22,25]$. The $c p h A$ and $\operatorname{cph} B$ genes are frequently clustered together, with the $c p h B$ gene located upstream from the $c p h A$ gene (Fig. 1B). This gene arrangement is conserved in about $90 \%$ of the cyanobacteria that produce cyanophycin (excluding Pseudanabaena and Planktothrix strains in which this clustering is generally not observed; checked at https://img.jgi.doe.gov/). In Anabaena, the two genes (termed $c p h B 1$ and $c p h A 1$, respectively, see next paragraph) are co-transcribed from promoters located 
upstream of $c p h B 1$, and $c p h A 1$ is further transcribed monocistronically from promoters located in the intergenic region [26].

A second cph gene cluster, in which the genes are divergent (Fig. 1B), has been described in Anabaena [26]. Because in Anabaena the genes in the cluster described in the previous paragraph (that is similar to the Synechocystis cluster) are responsible for more cyanophycin synthetase and cyanophycinase activities than the genes in the second cluster, the genes in the two clusters have been named $c h p A 1 / c p h B 1$ and $c p h A 2 / c p h B 2$, respectively [26]. The $c p h A 2$ gene has been found to encode a second type of cyanophycin synthetase that is widespread predominantly in $\mathrm{N}_{2}$-fixing cyanobacteria [27], in which the divergent arrangement of $\operatorname{cph} A 2$ and $c p h B 2$ is conserved in about $65 \%$ of the genomes containing a $c p h A 2$ gene. CphA2 lacks the Cterminal reaction center found in CphA1 and adds a $\beta$-aspartyl-arginine dipeptide to the poly- $\alpha$ aspartic acid backbone consuming one molecule of ATP per molecule of dipeptide incorporated. In those cyanobacteria that have $\mathrm{CphA} 2, \beta$-aspartyl-arginine can be reincorporated into cyanophycin under conditions that have not yet been defined (Fig. 1A). Whether CphB2 has any specific role in cyanophycin mobilization is unknown.

The full mobilization of cyanophycin involves the cleavage of the $\beta$-aspartyl-arginine dipeptide into aspartate and arginine carried out by isoaspartyl dipeptidase, which is related to plant-type asparaginases [28]. Isoaspartyl dipeptidase is composed of two subunits that result from the processing of the polypeptidic product of one gene. To distinguish this gene from the isoaspartyl dipeptidase-encoding gene from bacteria such as Escherichia coli, iadA, to which the cyanobacterial gene is not related, we shall term iadC the gene encoding the cyanobacterial isoaspartyl dipeptidase. In Anabaena and Synechocystis, iadC is open reading frame all3922 and sll0422, respectively. Interestingly, in the streamlined genome of the endosymbiotic cyanobacterium Richelia intracellularis HH01 (a symbiont of the diatom Hemiaulus hauckii [29]), the iadC gene is split into two consecutive genes, RintHH_8620 and RintHH_8610, which is consistent with the importance of producing isoaspartyl dipeptidase to work as two independent polypeptides.

\subsection{Physiology}

Cyanophycin generally accumulates in the cells under unbalanced growth conditions in the presence of sufficient nitrogen, e.g., when cells are starved for light, sulfur or phosphorus, or when they are incubated at low temperatures or with excess nitrogen-containing compounds (reviewed in [30]). Then, cyanophycin is degraded when balanced growth is resumed [31]. Although cyanophycin is found in many cyanobacteria, it seems not to be required for growth under standard laboratory conditions, since cphA mutants from both Synechocystis [32] and Anabaena spp. [26, 33] are viable. Only under nitrogen limitation and fluctuating light or 
light/dark cycles in Synechocystis [34], or under diazotrophic and high-light conditions in Anabaena variabilis [33], was the growth of a cphA or cphAl mutant, respectively, impaired.

In $\mathrm{N}_{2}$-fixing cyanobacteria such as the unicellular strain Cyanothece sp. ATCC 51142, which restricts $\mathrm{N}_{2}$ fixation to the dark period of diel cycles, cyanophycin accumulates in the dark, (when $\mathrm{N}_{2}$ fixation is operative) and is degraded during photosynthetic growth in the light [32]. Accumulation of recently fixed nitrogen in cyanophycin has also been proposed to be used by Trichodesmium erythraeum to temporally uncouple $\mathrm{CO}_{2}$ fixation and $\mathrm{N}_{2}$ fixation [11]. A further development in cyanophycin utilization is found in heterocystous cyanobacteria, in which refractile granules that are universally found at the poles of the heterocysts have been identified as cyanophycin $[35,36]$. In experiments of fixation of ${ }^{13} \mathrm{~N}$-labeled $\mathrm{N}_{2}$ by Anabaena cylindrica, aspartate and arginine were observed just after the primary products of $\mathrm{N}_{2}$ fixation (ammonia, glutamine and glutamate) were detected [37], which is likely the basis for a rapid incorporation of fixed nitrogen into cyanophycin. Consistently, cyanophycin synthetase activity (measured using aspartic acid or arginine as substrate) is higher in heterocysts than in vegetative cells of Anabaena [38], and the cphAl gene is expressed in heterocysts as well as in vegetative cells [26]. The cyanophycin granule of the heterocysts appears to be a place of transient accumulation of arginine and aspartate that are to be transferred to the adjacent vegetative cells. Thus, a $c p h B 1$ mutant of Anabaena accumulates cyanophycin granules in heterocysts (as well as in vegetative cells) and is impaired in diazotrophic growth (growth rate constant of the mutant is about $64 \%$ that of the wild type [26]). To complete the mobilization of cyanophycin, $\beta$-aspartyl-arginine produced by cyanophycinase has to be split into aspartate and arginine but, as shown in Anabaena, isoaspartyl dipeptidase accumulates at much higher levels in vegetative cells than in heterocysts, suggesting that the dipeptide is transferred as a nitrogen vehicle to the vegetative cells [39]. Interestingly, an iadC mutant of Anabaena is impaired in diazotrophic growth to a similar extent as the $c p h B 1$ mutant (growth rate constant of the iadC mutant is about $54 \%$ that of the wild type [39]). In summary, cyanophycin is not essential for cyanobacterial growth but appears to provide the cells with a transient storage of aspartate and arginine that improves the metabolic use of nitrogen.

\section{Sources of aspartate and arginine}

\subsection{Cellular synthesis}

In experiments of dark fixation of ${ }^{14} \mathrm{C}$-labeled $\mathrm{CO}_{2}$, Melvin Calvin and collaborators found that the earliest fixation product in Nostoc muscorum was aspartate [40], which likely resulted from carboxylation of phosphoenolpyruvate (PEP) to produce oxaloacetate and rapid transamination of oxaloacetate to produce aspartate (Fig. 2); more slowly, the second most abundant labeled product was glutamate. Anabaena is able to actively take up pyruvate through a tripartite ATP- 
independent periplasmic (TRAP) transporter [41], and in Anabaena cells incubated with [1${ }^{14} \mathrm{C}$ ]pyruvate significant accumulation of labeling in aspartate and glutamate has also been observed. This labeling pattern is consistent with carboxylation of pyruvate (via PEP) and (i) quick transamination of oxaloacetate to produce aspartate and (ii) metabolism through the tricarboxylic acid cycle to produce 2-oxoglutarate and, then, glutamate [42] (Fig. 2). A key enzyme encoded in cyanobacterial genomes that is involved in these reactions is PEP carboxylase (All4861 in Anabaena; Sl10920 in Synechocystis), which in addition to RuBisCo is an important $\mathrm{CO}_{2}$ fixation enzyme in cyanobacteria. In the case of metabolism of exogenously supplied pyruvate, PEP synthase (at least two orthologues present in Anabaena, All0635 and All3146/3147; one in Synechocystis, Slr0301) could be involved (Fig. 2). On the other hand, the genome of cyanobacteria such as Anabaena or Synechocystis bear several genes encoding putative aspartate aminotransferases. Five such genes have been characterized in Anabaena, and one of them (alr4853) was found to be needed for diazotrophic growth and to encode an enzyme with especially high aminotransferase activity, whereas the other gene products may have redundant activities [43].

The arginine biosynthesis pathway consists of two parts: (i) production of ornithine from glutamate and (ii) transformation of ornithine into arginine. The cyanobacteria produce ornithine from glutamate via the "cyclic pathway of ornithine synthesis" [44], in which glutamate is activated with an acetyl group transferred from acetyl-ornithine by ornithine acetyltransferase [45]. The genes encoding the corresponding enzymes can be detected in sequenced cyanobacterial genomes as exemplified in Figure 3 for Synechocystis and Anabaena. Additionally, the activity of some of these enzymes has been determined in some cyanobacterial cells, including vegetative cells and heterocysts of Anabaena or Nostoc spp. (see, e.g., [44, 46, 47]), and two genes (argC and $\arg D$ ) have been cloned by complementation of arginine auxotrophic mutants of Anabaena $[48,49]$.

$\mathrm{N}$-acetyl-glutamate semialdehyde dehydrogenase is the product of the $\arg C$ gene, and a second gene that encodes a similar enzyme has been found in Nostoc ellipsosporum and termed $\operatorname{argL}$ [50]. The two gene products share low similarity (27\% identity between the Anabaena proteins), and whereas $\mathrm{ArgC}$ is involved in production of arginine for protein synthesis, $\operatorname{ArgL}$ appears to be involved in production of arginine that is incorporated into cyanophycin [48, 50]. Although the genome of numerous heterocystous cyanobacteria bear both genes, the presence of the two genes is not a general feature in cyanobacteria (checked at https://img.jgi.doe.gov/), in which an $\arg L$-like gene (generally termed $\arg C$ ) is prevalent. The corresponding gene product must be involved in production of arginine for both protein and cyanophycin synthesis. The arg $J$ gene encoding ornithine acetyltransferase is also duplicated in Anabaena and a few other heterocystous cyanobacteria, but not in Synechocystis or the majority of cyanobacteria with sequenced genomes (checked at https://img.jgi.doe.gov/). The gene generally found in 
cyanobacteria is argJl and, in Anabaena, the ArgJ2 protein is 38\% identical to ArgJ1. To the best of our knowledge, the corresponding gene products have however not been characterized. Why some heterocystous cyanobacteria have got specialized $\operatorname{argCl\operatorname {arg}L}$ genes and duplicated argJl/argJ2 genes is unknown, but it would be of interest to investigate whether any of these genes shows cell-specific expression in the Anabaena filament.

In $\left[{ }^{14} \mathrm{C}\right] \mathrm{CO}_{2}$ fixation experiments with $N$. muscorum (both in the light and darkness), ${ }^{14} \mathrm{C}$ was also found incorporated into citrulline indicating an additional significant site of $\mathrm{CO}_{2}$ fixation, the synthesis of carbamoyl phosphate [40, 51] carried out by carbamoyl phosphate synthase [46] (Fig. 2), which is the product of the carA and carB genes (Alr1155 and Alr3809 in Anabaena). In the second part of the arginine biosynthetic pathway, ornithine carbamoyltransferase ( $\arg F$ gene product) incorporates carbamoyl phosphate into ornithine to produce citrulline [46] (Fig. 3). Mutants of $\arg F$ have been created in Synechocystis and Anabaena, and both of them are arginine auxotrophs $[52,53]$. The final steps of arginine biosynthesis are catalyzed by argininosuccinate synthase that incorporates aspartate with the consumption of ATP, and argininosuccinate lyase, whose activity has been measured in some cyanobacteria (see, e.g., [54]), that produces arginine releasing fumarate (Fig. 3).

In cyanobacteria, the $\arg B$ gene product, $\mathrm{N}$-acetyl-glutamate kinase, is subjected to feedback inhibition by the final product of the biosynthetic pathway, arginine [44]. The $\mathrm{P}_{\text {II }}$ protein ( $g \ln B$ gene product) transmits information on the $\mathrm{C}$ to $\mathrm{N}$ balance and energetic (ATP/ADP) status of the cells to several molecular targets [55]. Under nitrogen sufficiency (low C:N ratio) and a high energy status (low ADP levels), non-phosphorylated $\mathrm{P}_{\text {II }}$ trimer-MgATP complexes tightly bind to $\mathrm{N}$-acetyl-glutamate kinase limiting its sensitivity to arginine and increasing its enzymatic activity [56]. This leads to production of abundant arginine that can be incorporated into cyanophycin [57]. In contrast, under nitrogen deprivation (high C:N ratio), the cells accumulate 2-oxoglutarate that binds to the $\mathrm{P}_{\text {II }}$ trimer, which becomes phosphorylated preventing its binding to targets. Under these conditions, $\mathrm{N}$-acetyl-glutamate kinase is very sensitive to its allosteric inhibitor arginine, limiting production of arginine that is used for protein synthesis. Thus, $\mathrm{N}$ acetyl-glutamate kinase, which consumes ATP and participates in the first steps of the arginine biosynthetic pathway, is an important target for regulation of arginine biosynthesis with impact on the production of cyanophycin.

\subsection{Uptake from the extracellular medium}

Many cyanobacteria show an appreciable activity of uptake of amino acids, which is particularly high in the case of arginine transport in Synechocystis [58], and arginine has been shown to serve as a nitrogen source in different cyanobacteria [59-61]. The affinity of the cells for arginine is high ( $K_{\mathrm{s}}$ around $1 \mu \mathrm{M}$ or lower) in both Anabaena and Synechocystis $[60,61]$. In contrast, the affinity for aspartate in Anabaena is low ( $K_{\mathrm{s}}, 132 \mu \mathrm{M}$ [62]), whereas Synechocystis shows 
negligible uptake of this amino acid [58,63]. In many cyanobacteria, arginine is taken up by an ATP-binding cassette $(\mathrm{ABC})$ transporter for basic amino acids that consists of two types of subunits: BgtB (Alr3187, S111270), which has periplasmic substrate-binding and integral membrane (permease) domains (i.e., it has the primary structure of a fusion of both domains); and BgtA, (Alr4167, Slr1735) which is a nucleotide-binding domain or ATPase protein [64, 65]. To conform to the standard structure of $\mathrm{ABC}$ transporters [66], the functional Bgt transporter is likely composed of two copies of each subunit. Uptake of aspartate in Anabaena is mediated by an ABC transporter for acidic (and neutral polar) amino acids known as N-II transporter. This transporter is composed of the products of four genes that likely constitute an operon: natF (alr4164), encoding a periplasmic substrate-binding protein; natG (alr4165) and natH (alr4166), encoding transmembrane proteins; and bgtA (alr4167), encoding a nucleotide-binding domain [65]. BgtA is shared by the basic and acidic amino acid transporters as evidenced by the fact that its inactivation in Anabaena results in transport activities of Arg, Lys and Asp that are about $5 \%$ those of the wild type [65]. Total amino acids in the environment are commonly between 5 and $300 \mu \mathrm{M}$ in concentration [67], implying that uptake of aspartate and, especially, arginine from the extracellular medium can be significant in cyanobacteria that express the BgtBA and NatFGHBgtA transporters. On the other hand, Bgt-mediated uptake of ${ }^{14} \mathrm{C}$-labeled arginine has been key in the investigation of arginine utilization that will be discussed below.

\section{Arginine catabolism}

After mobilization of cyanophycin, aspartate and arginine have to be catabolized to make their nitrogen (and carbon) atoms available for metabolism. Whereas the mode of utilization of aspartate in cyanobacteria has not been specifically investigated, the utilization of arginine has been studied in detail in both Anabaena and Synechocystis.

Cell suspensions of Anabaena or Synechocystis supplemented with $\left[{ }^{14} \mathrm{C}\right] \operatorname{arginine}$ at low $\mu \mathrm{M}$ concentrations rapidly produce ${ }^{14} \mathrm{C}$-labeled proline and glutamate at substantial levels, with some production of ${ }^{14} \mathrm{C}$-labeled ornithine and glutamine being also detected [52, 68]. An example of such an experiment is shown in Figure 4. This pattern of labeling is the result of a catabolic pathway that involves two bifunctional enzymes: arginine-guanidine removing enzyme (AgrE; termed ArgZ by Zhang et al. [69]) and proline oxidase (PutA) [53], which together produce glutamate from arginine; glutamate can be further used by glutamine synthetase to incorporate ammonia producing glutamine [70]. AgrE is a protein of about 700 amino acid residues (Anabaena Alr4995, 703 residues; Synechocystis S111336, 705 residues) that has an N-terminal domain (residues 10-269 of the Anabaena enzyme) with an $\alpha / \beta$ propeller structure and a Cterminal domain (residues 285-696 of the Anabaena enzyme) homologous to an archaeal protein itself with two distinct domains (residues 285-381, similar to a domain in lysine-oxoglutarate 
reductase/saccharopine dehydrogenase enzymes; residues 462-696, similar to the NAD/FAD binding domain of deoxyhypusine synthases). The N-terminal domain of AgrE has arginine dihydrolase activity producing ornithine, $\mathrm{CO}_{2}$ and two ammonium molecules from arginine [53, 69] and the C-terminal domain has ornithine cyclodeaminase activity producing proline and ammonium from ornithine [53] (Fig. 5). Indeed, catabolism of exogenously supplied $\left[{ }^{14} \mathrm{C}\right]$ ornithine also produces ${ }^{14} \mathrm{C}$-labeled proline and glutamate (Fig. $4 \mathrm{a}$; see also [52, 53]). In the arginine catabolism pathway, proline is further catabolized to glutamate by a conventional PutA (Alr0540, Sl11561), predicted to have proline dehydrogenase and glutamate- $\gamma$-semialdehyde dehydrogenase activities, with $\Delta^{1}$-pyrroline-5-carboxylate that is spontaneously hydrated to glutamate- $\gamma$-semialdehyde as intermediate. Summing up, this pathway makes available to metabolism the four nitrogen atoms of arginine, three as ammonia and one as glutamate (Fig. 5).

The two enzymes of the arginine catabolic pathway, AgrE and PutA, may exert a mechanism of substrate tunneling, in which the product of the first domain of the enzyme (ornithine in AgrE, $\Delta^{1}$-pyrroline-5-carboxylate/glutamate- $\gamma$-semialdehyde in PutA) is transferred to the second domain avoiding release of the intermediate into the cytoplasm. This phenomenon has been amply investigated in the bacterial PutA protein [71] and is important to avoid futile cycles, i.e., the utilization of ornithine and $\Delta^{1}$-pyrroline-5-carboxylate in arginine and proline synthesis, respectively, under conditions that require catabolism of these amino acids. Nonetheless, at least in the case of AgrE, some amount of the intermediate may be released from the enzyme in vivo, as some ${ }^{14} \mathrm{C}$-labeled ornithine can be detected in physiological assays of catabolism of $\left[{ }^{14} \mathrm{C}\right]$ arginine $[52,53]$. Part of this ornithine is recycled to produce citrulline and arginine through the second part of the arginine biosynthetic pathway (Figs. 3 and 5). This has been shown in Synechocystis by inactivation of $\arg F$ (ornithine carbamoyltransferase), which decreases labeling from $\left[{ }^{14} \mathrm{C}\right]$ arginine or $\left[{ }^{14} \mathrm{C}\right]$ ornithine into citrulline and increases labeling into proline [52]. Recently, metabolomic analysis of Synechocystis upon nitrogen nutrition shifts has also shown the operation of this cycle [69]. Because arginine was thought to be catabolized by an arginase-like enzyme releasing ornithine and urea, the cycle was first referred to as urea cycle [52], but after the identification of the AgrE enzyme with the arginase dihydrolase activity of its $\mathrm{N}$-terminal domain, the cycle has been termed ornithine-ammonia cycle [69]. In this cycle, aspartate is incorporated by the argininosuccinate synthase reaction (Fig. 3), which has the important implication of possibly recovering aspartate (and, hence, one additional nitrogen atom) from cyanophycin (Fig. 5). This can represent a way of utilization of aspartate additional to that represented by aspartate aminotransferases. (Although these enzymes were described above for the biosynthesis of aspartate (Fig. 2), aminotransferases generally catalyze reversible reactions.) How the ornithine-ammonia cycle and the catabolic pathway to glutamate are balanced or whether 
one or the other pathway is prevalent under some particular physiological conditions remains to be elucidated.

When an agrE mutant of Anabaena is incubated with $\left[{ }^{14} \mathrm{C}\right]$ arginine, a ${ }^{14} \mathrm{C}$-labeled agmatine spot is occasionally observed in thin layer chromatography (see, e.g., Fig. 4b), indicating that the metabolic flux through arginine decarboxylase is increased. Arginine decarboxylase (speA gene product, All3401) is the first enzyme in a polyamine biosynthesis pathway that in Anabaena produces sym-homospermidine [72]. On the other hand, two arginine decarboxylase-encoding genes and their encoded proteins (Slr1312 and Slr0662) have recently been characterized to be involved in spermidine synthesis in Synechocystis [73]. The different polyamines accumulated in Anabaena and Synechocystis reflect the observation that heterocystous cyanobacteria specifically accumulate sym-homospermidine that is needed for heterocyst differentiation [72, 74], whereas in Synechocystis spermidine content negatively correlates with biofilm formation [73].

\section{Co-occurrence of cyanophycin, AgrE/PutA and arginine and aspartate uptake}

The scheme in Figure 5 illustrates how the arginine catabolic pathway and the ornithine-ammonia cycle can be involved in the utilization of arginine taken up from the outer medium or released from cyanophycin in cyanobacterial Anabaena and Synechocystis models. To address how spread these metabolic options are in the phylum Cyanobacteria, we have performed a search for the corresponding genes in a number of sequenced cyanobacterial genomes. As a guide of genomes to be searched, we have used the phylogenetic tree of Shih et al. [15]. The data obtained are detailed in supplementary Table 1 and schematically summarized in Figure 6. Cyanophycin biosynthesis and arginine utilization genes are widespread in cyanobacteria other than the marine Prochlorococcus and Synechococcus (clade C1) and the well-known Synechococcus elongatus (clade $\mathrm{C} 2$ ); thus, the $\alpha$-cyanobacteria (clade $\mathrm{C} 1$ ) specifically lack cyanophycin and the arginine catabolic AgrE/PutA pathway. The presence of cyanophycin metabolism ( $c p h A, \operatorname{cphB}$, iadC) and arginine catabolic genes (agrE, putA) strongly correlate as shown in the Venn diagram in Figure 6 , and the correlation extends to the deeply divergent Gloeobacter violaceous and the recently discovered Gloeomargarita lithophora (supplementary Table 1). This correlation has only one notable exception: the marine endosymbiont Richelia intracellularis HH01 [29] (see supplementary Table 1), whose genome does not encode the AgrE-PutA pathway. On the other hand, the marine unicellular strain Synechocoocus sp. PCC 7336 (clade G) bears genes for both the AgrE-PutA pathway and BgtB but not for cyanophycin metabolism enzymes. The peculiarity of Synechococcus sp. PCC 7336 is that the evolutionary process of this strain, based on 16S rRNA sequences, differs from that of other Synechococcus strains but shares similarity with Gloeobacter violaceous, and this strain could therefore represent a new branch in the phylogenetic tree of 
cyanobacteria [75]. Overall, available data indicate that the AgrE/PutA pathway provides the normal mechanism for utilization of arginine released from cyanophycin in cyanobacteria.

Among the cyanobacteria that, in the test strains, bear the full set of cyanophycin metabolism and arginine catabolic genes ( $c p h A, c p h B$, iadC, agrE, putA), about $43 \%$ also contain the high-affinity basic amino acid transporter Bgt (Fig. 6, Venn diagram). (The presence of the Bgt transporter was searched using the BgtB protein as query; the nucleotide-binding domain, BgtA, was not used because it is also a component of the N-II transporter and, additionally, can be easily confused with the nucleotide-binding domain of other $\mathrm{ABC}$ transporters.) The Bgt transporter is widely present in distant cyanobacterial groups, although it is not found in the deeply divergent Gloeobacter violaceous and Gloeobacter kilaueensis JS1. It appears that, taking advantage of the presence of an efficient arginine catabolic pathway (AgrE/PutA), many cyanobacteria have acquired the efficient Bgt transporter that allows the utilization of arginine that may be found in their natural habitats.

The N-II transporter that is involved in uptake of aspartate was searched in the cyanobacterial genomes using the periplasmic substrate-binding protein NatF and the integral membrane component NatH as queries. The N-II transporter was found to be widespread in cyanobacteria, being present in about $77 \%$ of the test strains and about $76 \%$ of the strains that produce cyanophycin. It was previously known that the N-II transporter is absent from Synechocystis [58, 63, 64] and present in S. elongatus [76], strains that produce and does not produce cyanophycin, respectively. In spite of the fact that a strict correlation between the presence of the N-II transporter and cyanophycin is not found, the wide distribution of this transporter in cyanobacteria may permit the uptake of aspartate that, when available together with arginine, could be utilized at least in part by the ornithine-ammonia cycle.

\section{Concluding remarks}

The capability to produce cyanophycin is widespread in $\beta$-cyanobacteria, whereas it is absent from $\alpha$-cyanobacteria. Based on the presence of the nitrogen-rich arginine as one of the cyanophycin constituting amino acids, the cyanophycin granules provide the cells with a dynamic reservoir of nitrogen. This role as a reservoir appears to be especially relevant in $\mathrm{N}_{2}$-fixing cyanobacteria, in which recently fixed nitrogen can be transitorily stored in cyanophycin. Additionally, in the case of heterocystous cyanobacteria, cyanophycin plays a central role as a source of $\beta$-aspartyl arginine, a dipeptide that serves as a vehicle for the intercellular transfer of nitrogen. The physiology of cyanophycin accumulation and mobilization has been studied for decades, but the pathway for arginine catabolism has been elucidated only recently. The AgrE/PutA pathway makes available to metabolism the four nitrogen atoms of arginine, but a variant of the pathway, the so-called ornithine-ammonia cycle, serves to recover and make 
available to metabolism the nitrogen atom of aspartate as well. Future work should clarify the balance between the accumulation and mobilization of cyanophycin and the utilization of arginine and aspartate in cyanobacterial metabolism.

\section{Acknowledgments}

We thank Antonia Herrero (CSIC, Seville) for a critical reading of the manuscript. Work in E.F.'s lab was supported by grant number BFU2017-88202-P from the Spanish Government co-financed by the European Regional Development Fund. S.A. was supported by a Formación del Personal Investigador (FPI) fellowship/contract and M.B. was supported by a Juan de la Cierva contract, both from the Spanish Government.

\section{Author contributions}

E.F. conceived the review and wrote the manuscript; S.A. performed database analysis; M.B. performed database analysis, drafted parts of the manuscript and provided experimental data. All authors made manuscript revisions and agree with submission.

\section{Conflict of interest}

The authors declare that they have no conflict of interest. 


\section{References}

[1] Flores E, Herrero A, The cyanobacteria: morphological diversity in a photoautotrophic lifestyle. Perspect Phycol 1 (2014) 63-72

[2] Turmo A, Gonzalez-Esquer CR, Kerfeld CA, Carboxysomes: metabolic modules for $\mathrm{CO}_{2}$ fixation. FEMS Microbiol Lett 364 (2017) doi: 10.1093/femsle/fnx176.

[3] Rippka R, Deruelles J, Waterbury JB, Herdman M, Stanier RY, Generic assignments, strain histories and properties of pure cultures of cyanobacteria, J Gen Microbiol 111 (1979) 1-61

[4] Herrero A, Flores E, Genetic responses to carbon and nitrogen availability in Anabaena. Environ Microbiol 21(2019) 1-17.

[5] Stebegg R, Schmetterer G, Rompel A, Transport of organic substances through the cytoplasmic membrane of cyanobacteria. Phytochemistry 157 (2019) 206-218.

[6] Flores E, Herrero A, Compartmentalized function through cell differentiation in filamentous cyanobacteria, Nat Rev Microbiol 8 (2010) 39-50.

[7] Maldener I, Summers ML, Sukenik A, Cellular differentiation in filamentous cyanobacteria, in: Flores E, Herrero A (Eds.) The Cell Biology of Cyanobacteria, Caister Academic Press, Norfolk, UK (2014) pp. 263-291.

[8] Rae BD, Long BM, Badger MR, Price GD, Functions, compositions, and evolution of the two types of carboxysomes: polyhedral microcompartments that facilitate $\mathrm{CO}_{2}$ fixation in cyanobacteria and some proteobacteria. Microbiol Mol Biol Rev 77 (2013) 357-379.

[9] Fay P, Oxygen relations of nitrogen fixation in cyanobacteria, Microbiol Rev 56 (1992) 340-73.

[10] Staal M, Rabouille S, Stal LJ, On the role of oxygen for nitrogen fixation in the marine cyanobacterium Trichodesmium sp. Environ Microbiol 9 (2007) 727-736.

[11] Finzi-Hart JA, Pett-Ridge J, Weber PK, Popa R, Fallon SJ, Gunderson T, Hutcheon ID, Nealson $\mathrm{KH}$, Capone DG, Fixation and fate of $\mathrm{C}$ and $\mathrm{N}$ in the cyanobacterium Trichodesmium using nanometer-scale secondary ion mass spectrometry. Proc Natl Acad Sci USA 106 (2009) 6345-6350. Erratum in: Proc Natl Acad Sci USA 106 (2009) 9931.

[12] Toepel J, Welsh E, Summerfield TC, Pakrasi HB, Sherman LA, Differential transcriptional analysis of the cyanobacterium Cyanothece sp. strain ATCC 51142 during light-dark and continuous-light growth. J Bacteriol 190 (2008) 3904-3913.

[13] Herrero A, Stavans J, Flores E, The multicellular nature of filamentous heterocyst-forming cyanobacteria, FEMS Microbiol Rev 40 (2016) 831-854.

[14] Flores E, Picossi S, Valladares A, Herrero A, Transcriptional regulation of development in heterocystforming cyanobacteria. Biochim Biophys Acta Gene Regul Mech (2019) doi: 10.1016/j.bbagrm.2018.04.006.

[15] Shih PM, Wu D, Latifi A, Axen SD, Fewer DP, Talla E, Calteau A, Cai F, Tandeau de Marsac N, Rippka R, Herdman M, Sivonen K, Coursin T, Laurent T, Goodwin L, Nolan M, Davenport KW, Han CS, Rubin EM, Eisen JA, Woyke T, Gugger M, Kerfeld CA, Improving the coverage of the cyanobacterial phylum using diversity-driven genome sequencing. Proc Natl Acad Sci USA 110 (2013) 1053-1058.

[16] Tomitani A, Knoll AH, Cavanaugh CM, Ohno T, The evolutionary diversification of cyanobacteria: molecular-phylogenetic and paleontological perspectives. Proc Natl Acad Sci USA 103 (2006) 54427.

[17] Obst M, Steinbüchel A, Cynophycin - an ideal bacterial nitrogen storage material with unique chemical properties. Microbiol Monogr (2006) doi 10.1007/7171_007.

[18] Simon RD, Cyanophycin Granules from the blue-green alga Anabaena cylindrica: a reserve material consisting of copolymers of aspartic acid and arginine. Proc Natl Acad Sci USA 68 (1971) 265-267.

[19] Simon RD, Weathers P, Determination of the structure of the novel polypeptide containing aspartic acid and arginine which is found in Cyanobacteria. Biochim Biophys Acta 420 (1976) 165-176.

[20] Herrero A, Burnat M, Cyanophycin, a cellular nitrogen reserve material, in: Flores E, Herrero A (Eds.) The Cell Biology of Cyanobacteria, Caister Academic Press, Norfolk, UK (2014) pp. 211-219. 
[21] Watzer B, Forchhammer K, Cyanophycin: a nitrogen-rich reserve polymer, in: Tiwari A (Ed.) Cyanobacteria (2018) doi 10.5772/intechopen.7704.

[22] Ziegler K, Diener A, Herpin C, Richter R, Deutzmann R, Lockau W, Molecular characterization of cyanophycin synthetase, the enzyme catalyzing the biosynthesis of the cyanobacterial reserve material multi-L-arginyl-poly-L-aspartate (cyanophycin). Eur J Biochem. 254 (1998) 154-159.

[23] Richter R, Hejazi M, Kraft R, Ziegler K, Lockau W, Cyanophycinase, a peptidase degrading the cyanobacterial reserve material multi-L-arginyl-poly-L-aspartic acid (cyanophycin): molecular cloning of the gene of Synechocystis sp. PCC 6803, expression in Escherichia coli, and biochemical characterization of the purified enzyme. Eur J Biochem 263 (1999) 163-169.

[24] Berg H, Ziegler K, Piotukh K, Baier K, Lockau W, Volkmer-Engert R, Biosynthesis of the cyanobacterial reserve polymer multi-L-arginyl-poly-L-aspartic acid (cyanophycin): mechanism of the cyanophycin synthetase reaction studied with synthetic primers. Eur J Biochem 267 (2000) 55615570 .

[25] Law AM, Lai SW, Tavares J, Kimber MS, The structural basis of beta-peptide-specific cleavage by the serine protease cyanophycinase. J Mol Biol 392 (2009) 393-404.

[26] Picossi S, Valladares A, Flores E, Herrero A, Nitrogen-regulated genes for the metabolism of cyanophycin, a bacterial nitrogen reserve polymer: expression and mutational analysis of two cyanophycin synthetase and cyanophycinase gene clusters in heterocyst-forming cyanobacterium Anabaena sp. PCC 7120, J Biol Chem 279 (2004) 11582-11592.

[27] Klemke F, Nürnberg DJ, Ziegler K, Beyer G, Kahmann U, Lockau W, Volkmer T, CphA2 is a novel type of cyanophycin synthetase in N2-fixing cyanobacteria. Microbiology 162 (2016) 526-536.

[28] Hejazi M, Piotukh K, Mattow J, Deutzmann R, Volkmer-Engert R, Lockau W, Isoaspartyl dipeptidase activity of plant-type asparaginases. Biochem J 364 (2002) 129-136.

[29] Hilton JA, Foster RA, Tripp HJ, Carter BJ, Zehr JP, Villareal TA, Genomic deletions disrupt nitrogen metabolism pathways of a cyanobacterial diatom symbiont. Nat Commun 4 (2013) 1767.

[30] Allen MM, Cyanobacterial cell inclusions. Annu Rev Microbiol 38 (1984) 1-25.

[31] Mackerras, AH, de Chazal NM, Smith GD, Transient accumulation of cyanophycin in Anabaena cylindrical and Synechocystis 6308. J. Gen. Microbiol 136 (1990) 2057-2065.

[32] Li H, Sherman DM, Bao S, Sherman LA, Pattern of cyanophycin accumulation in nitrogen-fixing and non-nitrogen-fixing cyanobacteria. Arch Microbiol 176 (2001) 9-18.

[33] Ziegler K, Stephan DP, Pistorius EK, Ruppel HG, Lockau W, A mutant of the cyanobacterium Anabaena variabilis ATCC 29413 lacking cyanophycin synthetase: growth properties and ultrastructural aspects. FEMS Microbiol Lett 196 (2001) 13-18.

[34] Watzer B, Forchhammer K, Cyanophycin synthesis optimizes nitrogen utilization in the unicellular cyanobacterium Synechocystissp. PCC 6803. Appl Environ Microbiol (2018) doi: 10.1128/AEM.01298-18.

[35] Lang NJ, Simon RD, Wolk CP, Correspondence of cyanophycin granules with structures granules in Anabaena cylindrica. Arch Mikrobiol 83 (1972) 313-320.

[36] Sherman DM, Tucker D, Sherman LA, Heterocyst development and localization of cyanophycin in $\mathrm{N}_{2}$-fixing cultures of Anabaena sp. PCC 7120 (Cyanobacteria). J Phycol 36 (2000) 932-941.

[37] Wolk CP, Thomas J, Shaffer PW, Austin SM, Galonsky A, Pathway of nitrogen metabolism after fixation of ${ }^{13} \mathrm{~N}$-labeled nitrogen gas by the cyanobacterium, Anabaena cylindrica. J Biol Chem 251 (1976) 5027-5034.

[38] Gupta M, Carr NG, Enzyme activities related to cyanophycin metabolism in heterocysts and vegetative cells of Anabaena spp. J Gen Microbiol 125 (1981) 17-23.

[39] Burnat M, Herrero A, Flores E, Compartmentalized cyanophycin metabolism in the diazotrophic filaments of a heterocyst-forming cyanobacterium. Proc Natl Acad Sci USA 111 (2014) 3823-3828.

[40] Moses V, Holm-Hansen O, Calvin M, Nonphotosynthetic fixation of carbon dioxide by three microorganisms. J Bacteriol 77 (1959) 70-8.

[41] Pernil R, Herrero A, Flores E, A TRAP transporter for pyruvate and other monocarboxylate 2-oxoacids in the cyanobacterium Anabaena sp. strain PCC 7120. J Bacteriol 192 (2010) 6089-6092. 
[42] Pernil R, Herrero A, Flores E, Catabolic function of compartmentalized alanine dehydrogenase in the heterocyst-forming cyanobacterium Anabaena sp. strain PCC 7120. J Bacteriol 192 (2010) 51655172.

[43] Xu X, Gu L, He P, Zhou R, Characterization of five putative aspartate aminotransferase genes in the N2-fixing heterocystous cyanobacterium Anabaena sp. strain PCC 7120. Microbiology 161 (2015) 1219-1230.

[44] Hoare DS, Hoare SL, Feedback regulation of arginine biosynthesis in blue-green algae and photosynthetic bacteria. J Bacteriol 92 (1966) 375-379.

[45] Cunin R, Glansdorff N, Piérard A, Stalon V, Biosynthesis and metabolism of arginine in bacteria. Microbiol Rev 50 (1986) 314-352.

[46] Holm-Hansen O, Brown GW Jr, Ornithine cycle enzymes in the blue-green alga Nostioc muscorum. Plant Cell Physiol 4 (1963) 299-306.

[47] Gupta M, Carr NG, Enzymology of arginine metabolism in heterocyst-forming cyanobacteria. FEMS Microbiol Lett 12 (1981) 179-181.

[48] Floriano B, Herrero A, Flores E, Isolation of arginine auxotrophs, cloning by mutant complementation, and sequence analysis of the $\arg C$ gene from the cyanobacterium Anabaena species PCC 7120. Mol Microbiol 6 (1992) 2085-2094.

[49] Floriano B, Herrero A, Flores E, Analysis of expression of the $\arg C$ and $\arg D$ genes in the cyanobacterium Anabaena sp. strain PCC 7120. J Bacteriol 176 (1994) 6397-6401.

[50] Leganés F, Fernández-Piñas F, Wolk CP, A transposition-induced mutant of Nostoc ellipsosporum implicates an arginine-biosynthetic gene in the formation of cyanophycin granules and of functional heterocysts and akinetes. Microbiology 144 (1998) 1799-1805.

[51] Linko P, Holm-Hansen O, Bassham JA, Calvin M, Formation of radioactive citrulline during photosynthetic ${ }^{14} \mathrm{CO}_{2}$-fixation by blue-green algae. J Exp Bot 8 (1957) 147-154.

[52] Quintero MJ, Muro-Pastor AM, Herrero A, Flores E, Arginine catabolism in the cyanobacterium Synechocystis sp. strain PCC 6803 involves the urea cycle and arginase pathway. J Bacteriol 182 (2000) 1008-1015.

[53] Burnat M, Picossi S, Valladares A, Herrero A, Flores E, Catabolic pathway of arginine in Anabaena involves a novel bifunctional enzyme that produces proline from arginine. Mol Microbiol (2019) doi: 10.1111/mmi.14203.

[54] Troshina O, Jansson E, Lindblad P, Ornithine cycle in Nostoc PCC 73102: presence of an in vitro functional argininosuccinate lyase. FEMS Microbiol Lett 152 (1997) 75-81.

[55] Forchhammer K, $\mathrm{P}_{\mathrm{II}}$ signal transducers: novel functional and structural insights. Trends Microbiol 16 (2008) 65-72.

[56] Forchhammer K, Lüddecke J, Sensory properties of the $\mathrm{P}_{\text {II }}$ signalling protein family. FEBS J 283 (2016) 425-437.

[57] Maheswaran M, Ziegler K, Lockau W, Hagemann M, Forchhammer K, $\mathrm{P}_{\mathrm{II}}$-regulated arginine synthesis controls accumulation of cyanophycin in Synechocystis sp. strain PCC 6803. J Bacteriol 188 (2006) 2730-2734.

[58] Montesinos ML, Herrero A, Flores E, Amino acid transport in taxonomically diverse cyanobacteria and identification of two genes encoding elements of a neutral amino acid permease putatively involved in recapture of leaked hydrophobic amino acids. J Bacteriol 179 (1997) 853-862.

[59] Neilson AH, Larsson T, The utilization of organic nitrogen for growth of algae: physiological aspects. Physiol Plant 48 (1980) 542- 553.

[60] Herrero A, Flores E, Transport of basic amino acids by the dinitrogen-fixing cyanobacterium Anabaena PCC 7120. J Biol Chem 265 (1990) 3931-3935.

[61] Flores E, Muro-Pastor AM, Mutational and kinetic analysis of basic amino acid transport in the cyanobacterium Synechocystis sp. PCC 6803. Arch Microbiol 154 (1990) 521-527.

[62] Montesinos ML, Herrero A, Flores E. Amino acid transport systems required for diazotrophic growth in the cyanobacterium Anabaena sp. strain PCC 7120. J Bacteriol 177 (1995) 3150-3157. 
[63] Labarre J, Thuriaux P, Chauvat F, Genetic analysis of amino acid transport in the facultatively heterotrophic cyanobacterium Synechocystis sp. strain 6803. J Bacteriol 169 (1987) 4668-4673.

[64] Quintero MJ, Montesinos ML, Herrero A, Flores E, Identification of genes encoding amino acid permeases by inactivation of selected ORFs from the Synechocystis genomic sequence. Genome Res 11 (2001) 2034-2040.

[65] Pernil R, Picossi S, Mariscal V, Herrero A, Flores E, ABC-type amino acid uptake transporters Bgt and N-II of Anabaena sp. strain PCC 7120 share an ATPase subunit and are expressed in vegetative cells and heterocysts. Mol Microbiol 67 (2008) 1067-1080.

[66] Locher KP, Mechanistic diversity in ATP-binding cassette (ABC) transporters. Nat Struct Mol Biol 23 (2016) 487-493.

[67] Hobbie JE, Hobbie EA, Microbes in nature are limited by carbon and energy: the starving-survival lifestyle in soil and consequences for estimating microbial rates. Front Microbiol 4 (2013) 324.

[68] Burnat M, Flores E, Inactivation of agmatinase expressed in vegetative cells alters arginine catabolism and prevents diazotrophic growth in the heterocyst-forming cyanobacterium Anabaena. MicrobiologyOpen 3 (2014) 777-792.

[69] Zhang H, Liu Y, Nie X, Liu L, Hua Q, Zhao GP, Yang C. The cyanobacterial ornithine-ammonia cycle involves an arginine dihydrolase. Nat Chem Biol 14 (2018) 575-581.

[70] Muro-Pastor MI, Reyes JC, Florencio FJ, Ammonium assimilation in cyanobacteria. Photosynth Res 83 (2005) 135-150.

[71] Liu LK, Becker DF, Tanner JJ, Structure, function, and mechanism of proline utilization A (PutA). Arch Biochem Biophys 632 (2017) 142-157.

[72] Burnat M, Li B, Kim SH, Michael AJ, Flores E, Homospermidine biosynthesis in the cyanobacterium Anabaena requires a deoxyhypusine synthase homologue and is essential for normal diazotrophic growth. Mol Microbiol 109 (2018) 763-780.

[73] Kera K, Nagayama T, Nanatani K, Saeki-Yamoto C, Tominaga A, Souma S, Miura N, Takeda K, Kayamori S, Ando E, Higashi K, Igarashi K, Uozumi N, Reduction of spermidine content resulting from inactivation of two arginine decarboxylases increases biofilm formation in Synechocystis sp. strain PCC 6803. J Bacteriol 200 (2018) e00664-17

[74] Hamana K, Furuchi T, Hayashi H, Niitsu M, Additional analysis of cyanobacterial polyamines Distributions of spermidine, homospermidine, spermine, and thermospermine within the phylum Cyanobacteria-. Microb Resour Syst 32 (2016) 179-186.

[75] Li Y, Rao NN, Yang Y, Zhang Y, Gu YN, Gene annotation and functional analysis of a newly sequenced Synechococcus strain. Genet Mol Res 14 (2015) 12416-12426.

[76] Escudero L, Mariscal V, Flores E. Functional dependence between septal protein SepJ from Anabaena sp. strain PCC 7120 and an amino acid ABC-type uptake transporter. J Bacteriol 197 (2015) 27212730. 


\section{Figure Legends}

Fig. 1. Cyanophycin synthesis and degradation. (A) Cyanophycin elongation is carried out by the CphA1 type of cyanophycin synthetase, which adds aspartate and arginine to a cyanophycin polypeptide, or by the CphA2 type that adds $\beta$-aspartyl-arginine. Cyanophycin degradation is accomplished by the sequential action of cyanophycinase $(\mathrm{CphB})$ and isoaspartyl dipeptidase (IadC). (B) Genomic context of the cphA and cphB genes in Synechocystis and of cphA1, cphB1, cphA2 and cphB2 in Anabaena (also known as Nostoc) (taken from https://img.jgi.doe.gov/). These gene arrangements are highly conserved in cyanobacteria that produce cyanophycin, although $c p h A 2$ and $c p h B 2$ are generally restricted to $\mathrm{N}_{2}$-fixing strains.

Fig. 2. Scheme of the central carbon metabolism and synthesis of aspartate in cyanobacteria. Three sites of carbon fixation are indicated $\left(\mathrm{CO}_{2}\right.$ or $\mathrm{HCO}_{3}{ }^{-}$in red color): the Calvin-BensonBassham (CBB) cycle, phosphoenolpyruvate (PEP) carboxylase and carbamoylphosphate synthase. The possible incorporation of exogenously supplied pyruvate by means of PEP synthase is also indicated. The ammonium-assimilating glutamine synthetase-glutamate synthase (GS/GOGAT) cycle is highlighted in blue color in the lower-right part of the scheme $([\mathrm{H}]$, reducing power, normally provided to GOGAT as reduced ferredoxin). The dashed line and arrow indicate the final steps of glycolysis and first steps of the tricarboxylic acid (TCA) cycle: pyruvate kinase, pyruvate dehydrogenase, citrate synthase, aconitase and isocitrate dehydrogenase.

Fig. 3. Arginine biosynthesis pathway in cyanobacteria. Enzyme and gene names, as well as the corresponding Anabaena and Synechocystis ORFs, are indicated.

Fig. 4. Catabolism of arginine and ornithine in Anabaena. (A) Filaments of wild-type Anabaena grown under $\mathrm{N}_{2}$-fixing conditions $\left(\mathrm{BG} 11_{0}\right)$ were incubated in the presence of $\left[{ }^{14} \mathrm{C}\right]$ arginine or $\left[{ }^{14} \mathrm{C}\right]$ ornithine for the indicated time. (B) Filaments of the Anabaena agrE mutant grown in BG11 medium were incubated in the presence of $\left[{ }^{14} \mathrm{C}\right]$ arginine for the indicated time. In both cases, metabolic products were analyzed by thin layer chromatography as described previously [Burnat \& Flores 2014]. In A, note the production of ornithine (Orn), proline and glutamate from arginine and the production of proline, glutamate and arginine from ornithine; the spots of citrulline and glutamine overlap; \#8 and 10 are unidentified metabolites. In B, note the production of agmatine (product of arginine decarboxylase) from arginine. White triangles point to the origin of the chromatographies.

Fig. 5. Pathways of utilization of arginine in cyanobacteria. Arginine can be taken up from the outer medium by an ABC transporter for basic amino acids (1) that consists of BgtB (fusion 
protein of a periplasmic substrate-binding domain and a transmembrane or permease domain) and BgtA (nucleotide-binding domain or ATPase). Additionally, arginine can be made available to metabolism through degradation of cyanophycin by cyanophycinase (2) and isoaspartyl dipeptidase (3). The arginine catabolism pathway consists of the bifunctional enzymes AgrE (which produces ammonia, $\mathrm{CO}_{2}$ and, as a reaction intermediate, ornithine) and PutA (which produces glutamate and additionally renders reducing power). A fraction of the ornithine produced in AgrE can be recycled by arginine biosynthetic enzymes ornithine carbamoyltransferase (4), argininosuccinate synthase (5) and argininosuccinate lyase (6), constituting an ornithine-ammonia cycle $(\mathrm{OAC})$. $\mathrm{CM}$, cytoplasmic membrane; $[\mathrm{H}]$, reducing power, predictably in the form of $\mathrm{FADH}_{2}$ (product of the proline dehydrogenase reaction) and NADPH (product of the glutamate- $\gamma$-semialdehyde dehydrogenase reaction); P5C/GSA, $\Delta^{1}$ pyrroline-5-carboxylate/glutamate- $\gamma$-semialdehyde.

Fig. 6. Distribution of cyanophycin biosynthesis and arginine (and aspartate) utilization genes in the cyanobacterial phylum. The phylogenetic scheme is adapted from Shih et al. [15]. Representative clades and morphological types of strains in each clade are indicated along with the taxonomic group (I to V) of Rippka et al. [3]. Search for the genes in the indicated cyanobacteria was performed by BLAST analysis using the Anabaena genes as query, complemented by searches using Synechocystis genes. Cyanophycin synthetase is specifically the CphA1-type protein. Ticks indicate the presence of the corresponding gene in $100 \%$ of strains in a clade (highlighted in yellow color), > $90 \%$ (green), > $70 \%$ (blue), > $50 \%$ (magenta), > $20 \%$ (grey). An empty space means absence of the corresponding gene. Detailed information is available in supplementary Table 1. Venn diagram shows the intersection of cyanophycin metabolism (CphA, CphB and IadC proteins) (blue), arginine catabolism (AgrE and PutA proteins) (red), arginine uptake (BgtB) (green) and aspartate uptake (NatFH) (yellow) proteins among the cyanobacterial strains analyzed. Acaryochloris marina MBIC11017 was the only strain that presents PutA but not AgrE, and it has been considered not to have the AgrE-PutA pathway in the analysis. Venn diagrams have been calculated and drawn using the tool from the Bioinformatics and Evolutionary Genomics web page (http://bioinformatics.psb.ugent.be/webtools/Venn/). 
Fig. 1

A

CphA1 (SIr2002, All3879)

[Asp-Arg]
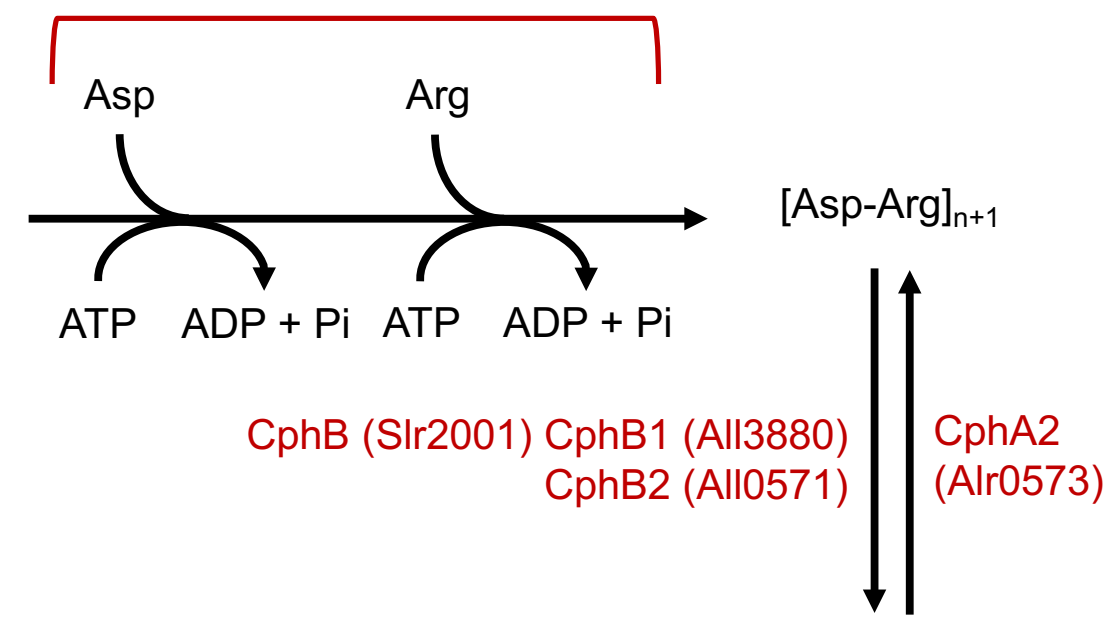

IadC (SII0422, All3922)

[Asp-Arg]

Aspartate + Arginine

$\beta$-Asp-Arg

B

cphA $\quad$ cphB

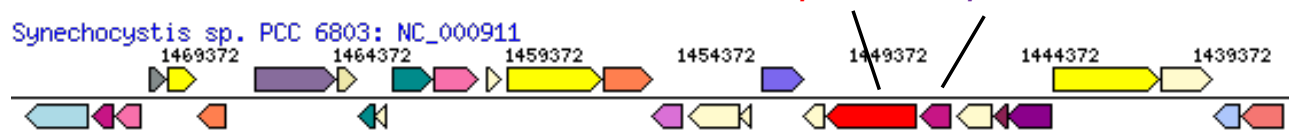

Nostoc sp. PCC 7120: NC_003272

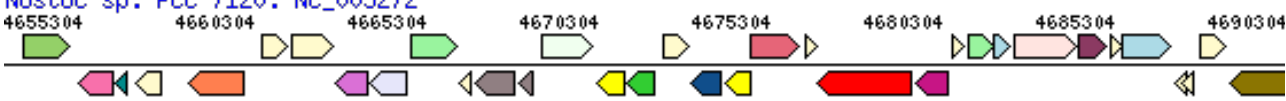

cphA1 сphB1

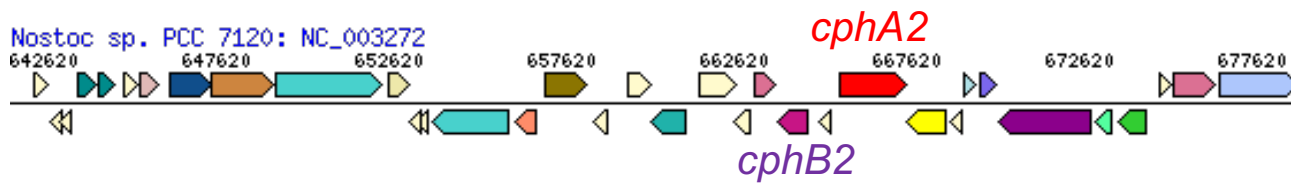


Fig. 2

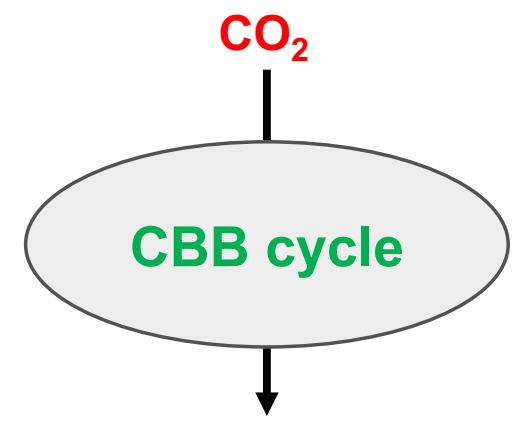

3-phosphoglycerate
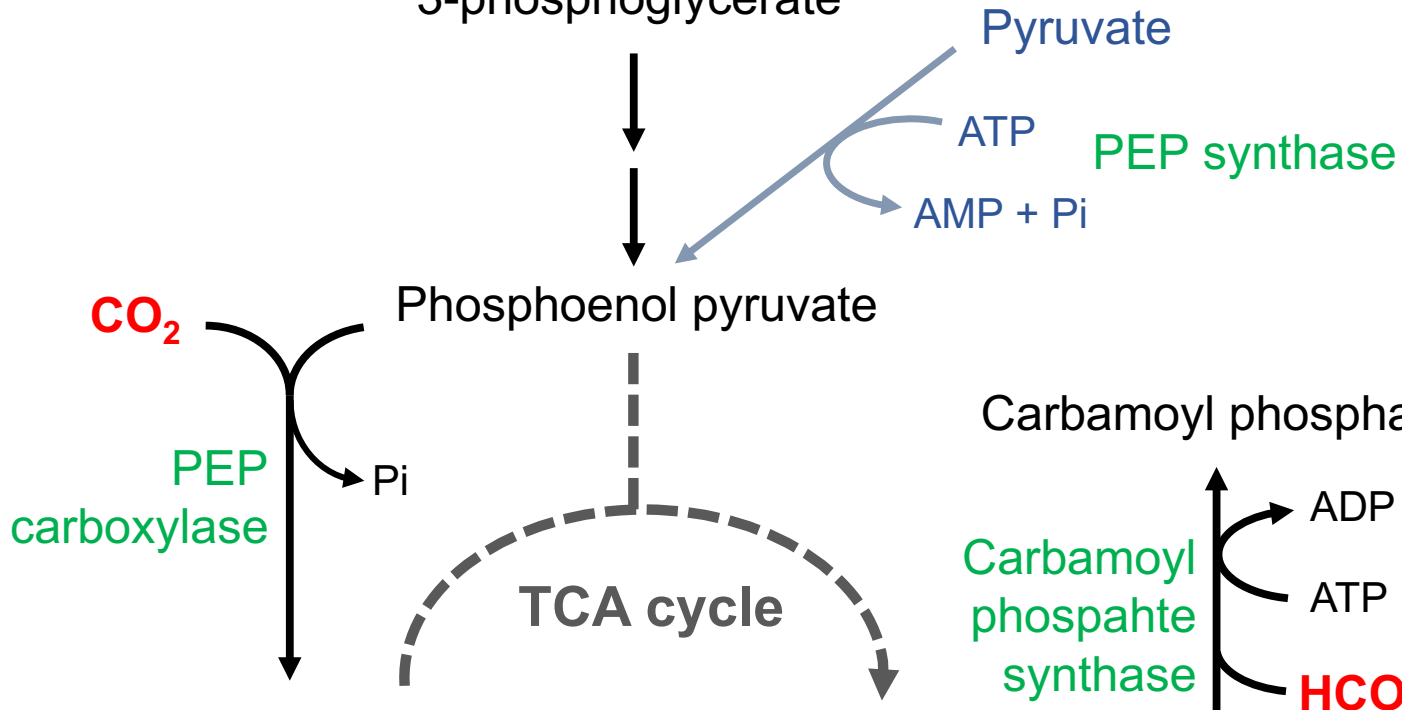

Oxaloacetate
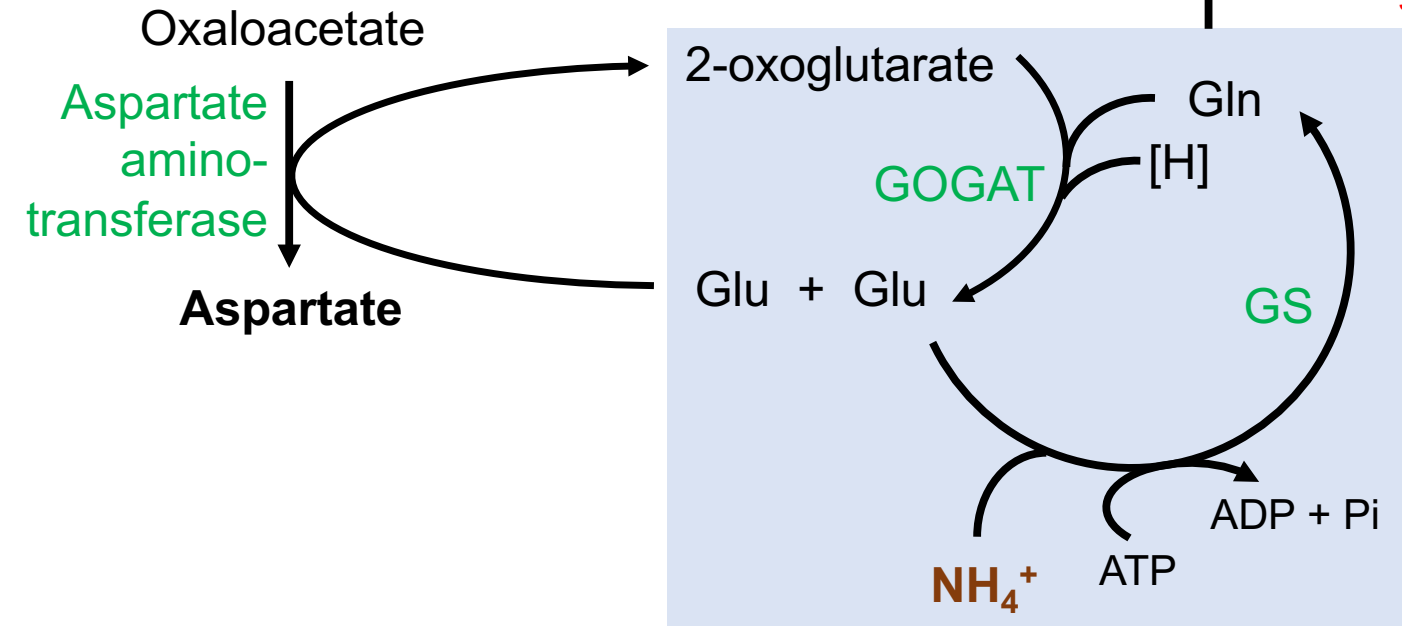

Carbamoyl phosphate

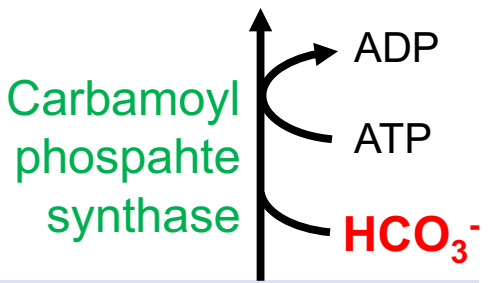


Fig. 3

\section{Glutamate}

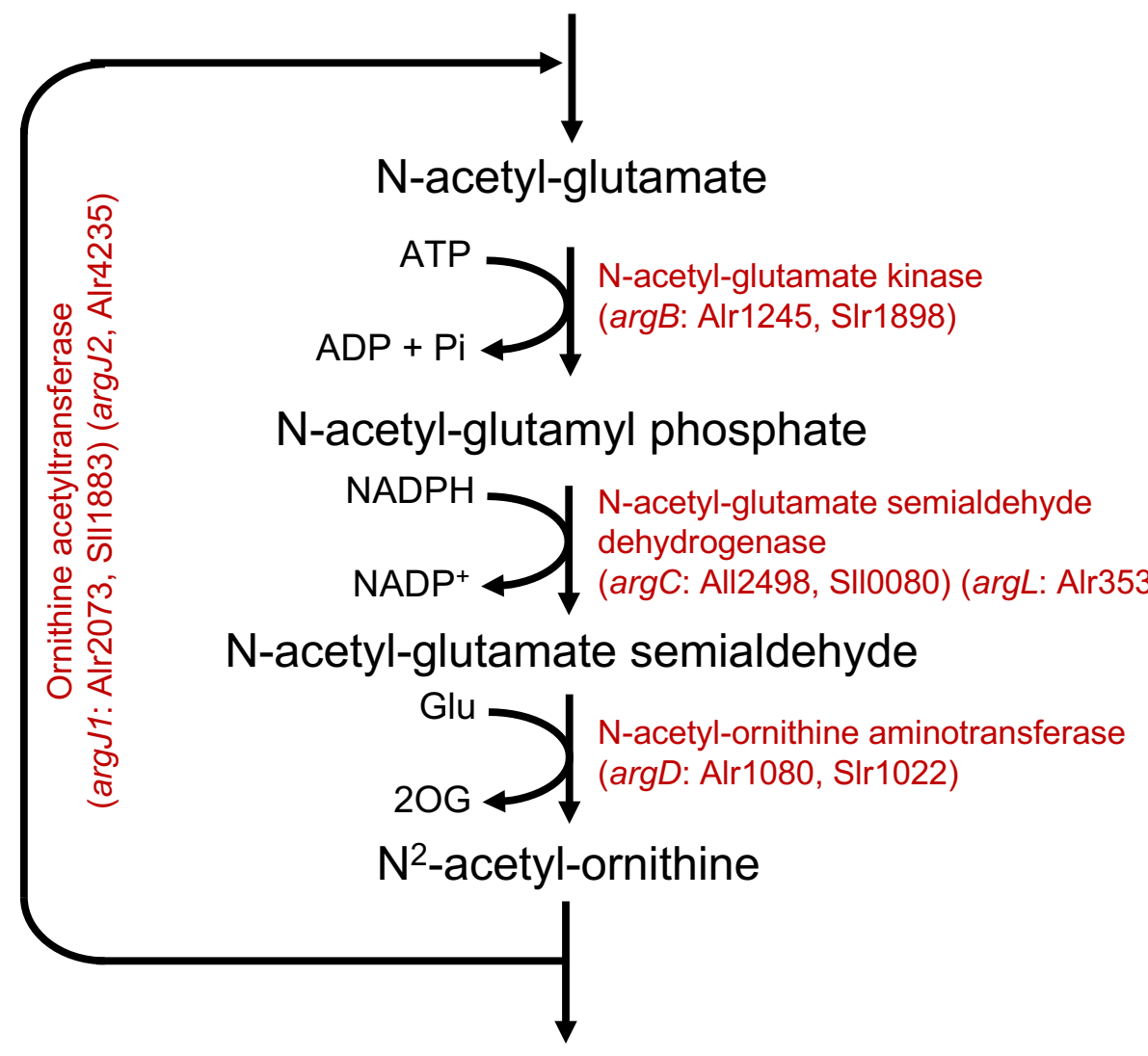

Ornithine

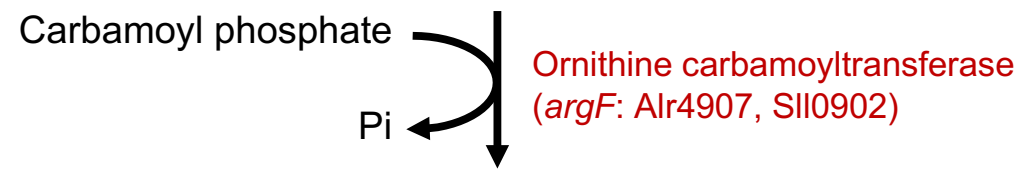

Citrulline

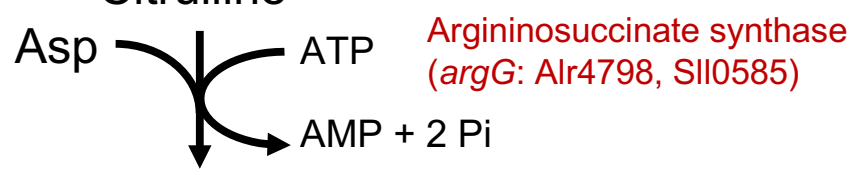

Argininosuccinate

Fumarate $\begin{aligned} & \text { Argininosuccinate lyase } \\ & \text { (argH: Alr3887, SIr1133) }\end{aligned}$

Arginine 
Fig. 4

A

\section{Anabaena sp. PCC 7120 (WT)}

$1 \mu \mathrm{M}\left[{ }^{14} \mathrm{C}\right]$ arginine $\mathrm{BG}_{11}, 30 \mathrm{~min}$

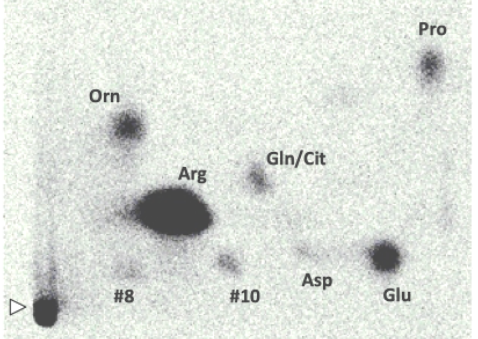

B

\section{Anabaena agrE mutant}

$1 \mu \mathrm{M}\left[{ }^{14} \mathrm{C}\right]$ arginine BG11, $10 \mathrm{~min}$

Agmatine

Arg

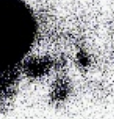


Fig. 5

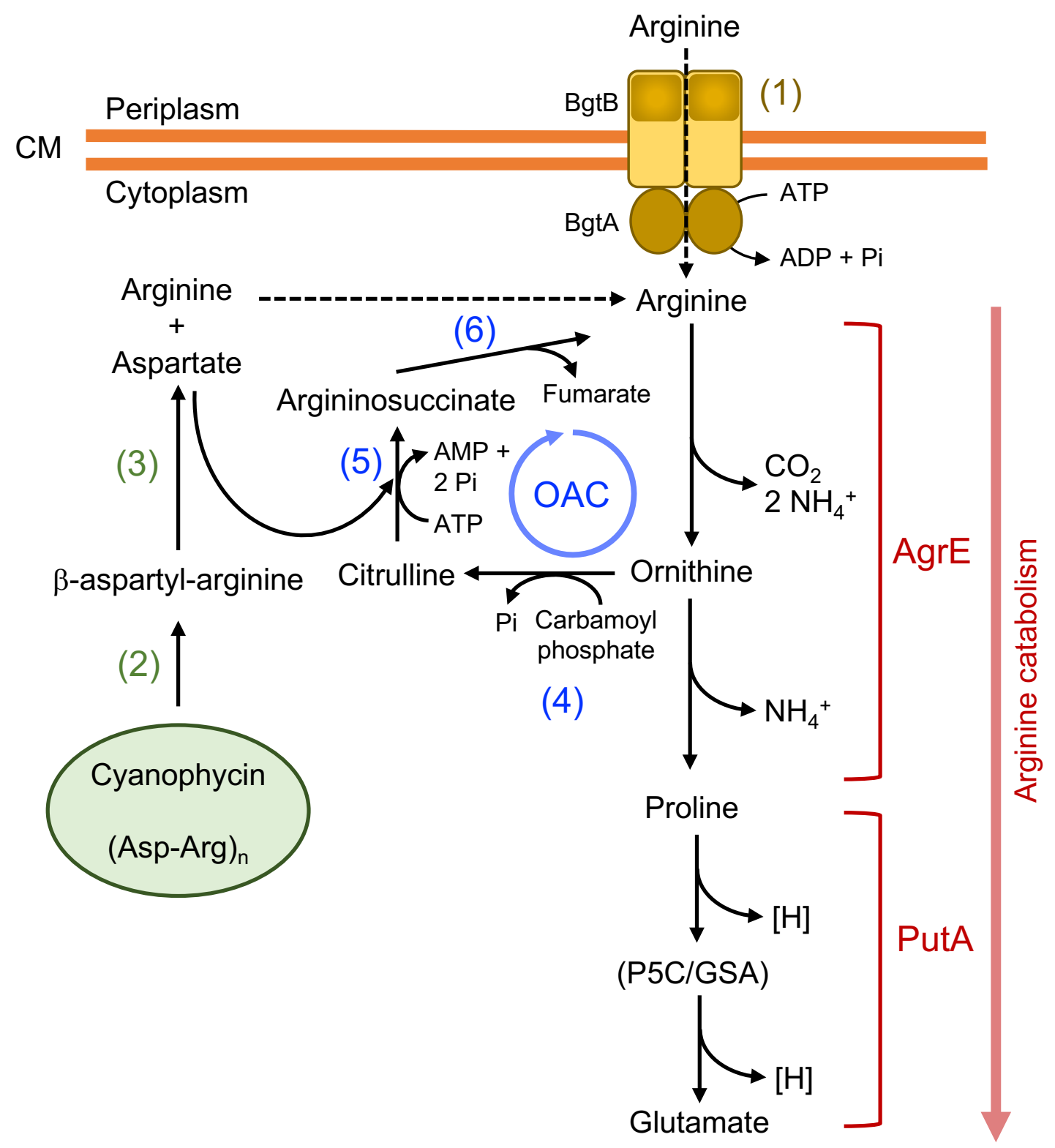


Fig. 6
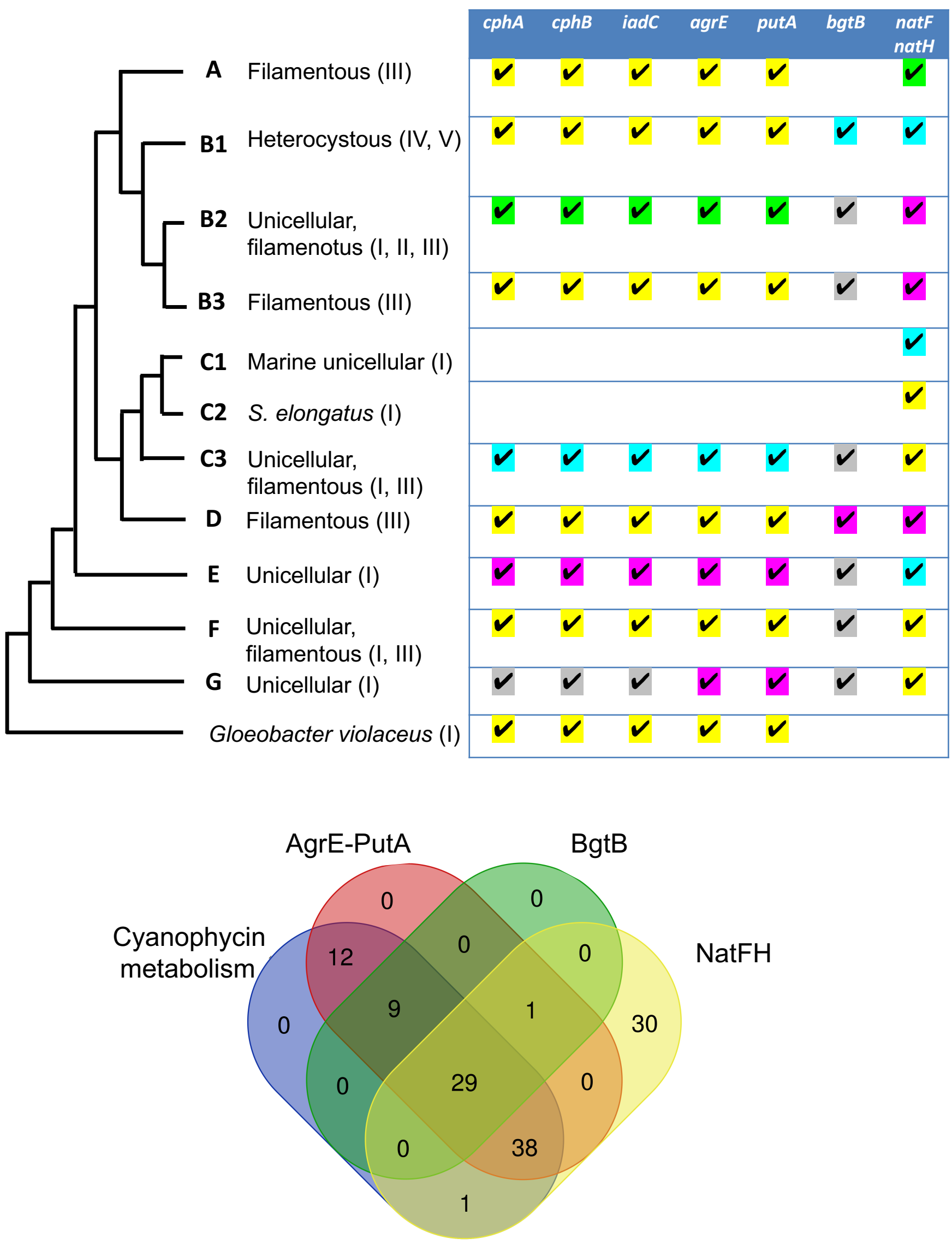

NatFH 
Supplementary Table 1. Cyanophycin metabolism, arginine catabolism, and arginine and aspartate transport genes in cyanobacteria.

The cyanobacteria included in the phylogenetic analysis of Shih et al. (2013) were used as test strains. The indicated Anabaena genes were used as query in BLAST analysis, which was completed by analysis using as query the corresponding Synechocystis genes (except cphA2, nat $F$ and nat $H$, not present in this organism). The presence of a gene in a strain is indicated by a check mark $(\checkmark)$. Every strain containing $c p h A 1$ contains $c p h B 1$, normally in an operon; $\dagger$ indicates that the clustering of the two genes is not conserved. For $c p h A 2$, I indicates the presence of a cphB2 gene in the neighbourhood as shown in Fig. 1.

\begin{tabular}{|c|c|c|c|c|c|c|c|c|}
\hline \multirow[t]{2}{*}{ Clade/Strain } & \multicolumn{8}{|c|}{ Gene } \\
\hline & $\begin{array}{l}\text { cphB1 } \\
\text { cphA1 }\end{array}$ & cphA2 & $i a d C$ & agrE & putA & bgtB & natF & natH \\
\hline \multicolumn{9}{|l|}{ Clade A } \\
\hline Trichodesmium erythraeum IMS101 & $\checkmark$ & & $\checkmark$ & $\checkmark$ & $\checkmark$ & & $\checkmark$ & $\checkmark$ \\
\hline Lyngbya sp. PCC 8106 & $\checkmark \dagger$ & & $\checkmark$ & $\checkmark$ & $\checkmark$ & & $\checkmark$ & $\checkmark$ \\
\hline Arthrospira platensis Paraca & $\checkmark$ & & $\checkmark$ & $\checkmark$ & $\checkmark$ & & $\sqrt{ }$ & $\checkmark$ \\
\hline Arthrospira platensis NIES-39 & $\checkmark$ & & $\checkmark$ & $\checkmark$ & $\checkmark$ & & $\checkmark$ & $\checkmark$ \\
\hline Arthrospira sp. PCC 8005 & $\checkmark$ & & $\checkmark$ & $\checkmark$ & $\checkmark$ & & $\checkmark$ & $\checkmark$ \\
\hline Arthrospira maxima CS-328 & $\checkmark$ & & $\checkmark$ & $\checkmark$ & $\checkmark$ & & $\checkmark$ & $\checkmark$ \\
\hline Oscillatoria nigro-viridis PCC 7112 & $\checkmark$ & $\checkmark 9$ & $\checkmark$ & $\checkmark$ & $\checkmark$ & & $\checkmark$ & $\checkmark$ \\
\hline Microcoleus vaginatus FGP-2 & $\checkmark$ & $\checkmark 9$ & $\checkmark$ & $\checkmark$ & $\checkmark$ & & $\checkmark$ & $\checkmark$ \\
\hline Oscillatoria sp. PCC 6506 & $\checkmark$ & $\checkmark 9$ & $\checkmark$ & $\checkmark$ & $\checkmark$ & & $\checkmark$ & $\checkmark$ \\
\hline Kamptonema formosum PCC 6407 & $\checkmark$ & $\checkmark 9$ & $\checkmark$ & $\checkmark$ & $\checkmark$ & & $\checkmark$ & $\checkmark$ \\
\hline Oscillatoria sp. PCC 10802 & $\checkmark$ & $\checkmark$ & $\checkmark$ & $\checkmark$ & $\checkmark$ & & & \\
\hline Oscillatoria acuminata PCC 6304 & $\checkmark$ & & $\checkmark$ & 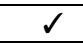 & $\checkmark$ & & $\checkmark$ & $\checkmark$ \\
\hline \multicolumn{9}{|l|}{ Clade B1 } \\
\hline Fischerella sp. PCC 9605 & $\checkmark$ & $\checkmark 9$ & $\checkmark$ & $\checkmark$ & $\checkmark$ & $\checkmark$ & & \\
\hline Fischerella sp. PCC 9431 & $\checkmark$ & $\checkmark 9$ & $\checkmark$ & $\checkmark$ & $\checkmark$ & $\checkmark$ & $\checkmark$ & $\checkmark$ \\
\hline Fischerella sp. PCC 9339 & $\checkmark$ & $\checkmark 9$ & $\checkmark$ & $\checkmark$ & $\checkmark$ & $\checkmark$ & $\checkmark$ & $\sqrt{ }$ \\
\hline Fischerella sp. JSC-11 & $\checkmark$ & & $\checkmark$ & $\checkmark$ & 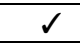 & $\checkmark$ & $\checkmark$ & $\checkmark$ \\
\hline Chlorogloeopsis sp. PCC 7702 & $\checkmark$ & $\checkmark 9$ & $\checkmark$ & $\checkmark$ & $\checkmark$ & $\checkmark$ & & \\
\hline Mastigocladopsis repens PCC 10914 & $\checkmark$ & $\sqrt{9}$ & $\checkmark$ & $\checkmark$ & $\checkmark$ & $\checkmark$ & & \\
\hline Calothrix sp. PCC 7103 & $\checkmark$ & $\sqrt{9}$ & $\checkmark$ & $\checkmark$ & $\checkmark$ & $\checkmark$ & $\checkmark$ & $\checkmark$ \\
\hline Calothrix sp. PCC 6303 & $\checkmark$ & & $\checkmark$ & $\checkmark$ & $\checkmark$ & & $\sqrt{ }$ & $\checkmark$ \\
\hline Nostoc sp. PCC 7524 & $\checkmark$ & $\checkmark 9$ & $\checkmark$ & $\checkmark$ & $\checkmark$ & $\checkmark$ & $\checkmark$ & $\checkmark$ \\
\hline Anabaena sp. PCC 7120 & $\checkmark$ & $\checkmark 9$ & $\checkmark$ & $\checkmark$ & $\checkmark$ & $\checkmark$ & $\checkmark$ & $\checkmark$ \\
\hline Anabaena variabilis ATCC 29413 & $\checkmark$ & $\checkmark 9$ & $\checkmark$ & $\checkmark$ & $\checkmark$ & $\checkmark$ & $\checkmark$ & $\checkmark$ \\
\hline Nostoc sp. PCC 7107 & $\sqrt{ }$ & $\checkmark 9$ & $\checkmark$ & $\checkmark$ & $\checkmark$ & $\checkmark$ & $\checkmark$ & $\checkmark$ \\
\hline Cylindrospermum stagnale PCC 7417 & $\checkmark$ & $\checkmark 9$ & $\checkmark$ & $\checkmark$ & $\checkmark$ & $\checkmark$ & $\checkmark$ & $\checkmark$ \\
\hline Anabaena cylindrica PCC 7122 & $\checkmark$ & $\checkmark 9$ & $\checkmark$ & $\checkmark$ & $\checkmark$ & $\checkmark$ & $\checkmark$ & $\checkmark$ \\
\hline Anabaena sp. PCC 7108 & $\checkmark$ & & $\checkmark$ & $\sqrt{4}$ & $\checkmark$ & & $\checkmark$ & $\checkmark$ \\
\hline Raphidiopsis brookii D9 & $\checkmark$ & & $\checkmark$ & $\checkmark$ & $\checkmark$ & & $\checkmark$ & $\checkmark$ \\
\hline Cylindrospermopsis raciborskii CS-505 & $\sqrt{ }$ & $\checkmark$ & $\checkmark$ & $\checkmark$ & $\checkmark$ & & $\checkmark$ & $\checkmark$ \\
\hline 'Nostoc azollae' 0708 & $\checkmark$ & $\checkmark$ & $\checkmark$ & $\checkmark$ & $\sqrt{2}$ & $\checkmark$ & $\checkmark$ & $\checkmark$ \\
\hline Nodularia spumignea CCY9414 & $\checkmark$ & $\checkmark$ & $\checkmark$ & $\checkmark$ & $\checkmark$ & & $\checkmark$ & $\checkmark$ \\
\hline Calothrix sp. PCC 7507 & $\checkmark$ & $\checkmark$ & $\checkmark$ & $\checkmark$ & $\checkmark$ & $\checkmark$ & $\checkmark$ & $\checkmark$ \\
\hline Microchaete PCC 7126 & $\checkmark$ & $\checkmark$ & $\checkmark$ & $\checkmark$ & $\checkmark$ & $\checkmark$ & $\checkmark$ & $\checkmark$ \\
\hline Nostoc puntiforme PCC 73102 & $\checkmark$ & $\checkmark 9$ & $\checkmark$ & 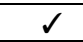 & $\checkmark$ & $\checkmark$ & & \\
\hline Scytomena hofmanni UTEX 2349 & $\checkmark$ & $\sqrt{9}$ & $\checkmark$ & $\checkmark$ & $\checkmark$ & & & \\
\hline Rivularia sp. PCC 7116 & $\checkmark$ & & $\checkmark$ & $\checkmark$ & $\checkmark$ & & $\checkmark$ & $\checkmark$ \\
\hline Synechocystis sp. PCC 7509 & $\checkmark$ & $\checkmark 9$ & $\checkmark$ & $\checkmark$ & $\checkmark$ & $\checkmark$ & & \\
\hline Gloeocapsa sp. PCC 7428 & $\checkmark$ & $\checkmark 9$ & $\checkmark$ & $\checkmark$ & $\checkmark$ & $\checkmark$ & $\checkmark$ & $\checkmark$ \\
\hline Chroococcidiopsis thermalis PCC 7203 & $\checkmark$ & $\checkmark 9$ & $\checkmark$ & 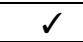 & $\checkmark$ & $\checkmark$ & $\checkmark$ & $\checkmark$ \\
\hline \multicolumn{9}{|l|}{ Clade B2 } \\
\hline \multicolumn{9}{|l|}{ Halothece sp. PCC 7418} \\
\hline Spirulina subsalsa PCC 9445 & $\checkmark$ & & $\checkmark$ & $\checkmark$ & $\checkmark$ & & $\checkmark$ & $\checkmark$ \\
\hline Spirulina major PCC 6313 & $\checkmark$ & & $\sqrt{ }$ & 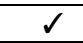 & $\checkmark$ & & $\checkmark$ & $\checkmark$ \\
\hline \multicolumn{9}{|l|}{ Atelocyanobacterium thalassa UCYN-A } \\
\hline Cyanothece sp. CCY0110 & $\checkmark$ & $\checkmark 9$ & $\checkmark$ & $\checkmark$ & $\checkmark$ & & $\checkmark$ & $\checkmark$ \\
\hline Cyanothece sp. ATCC 51472 & $\checkmark$ & & $\checkmark$ & $\checkmark$ & $\checkmark$ & & $\checkmark$ & $\checkmark$ \\
\hline
\end{tabular}




\begin{tabular}{|c|c|c|c|c|c|c|c|c|}
\hline Cyanothece sp. ATCC 51142 & $\checkmark$ & & $\checkmark$ & $\checkmark$ & $\checkmark$ & & $\checkmark$ & $\checkmark$ \\
\hline Crocosphaera watsonii WH 0003 & $\checkmark$ & & $\checkmark$ & $\sqrt{4}$ & $\checkmark$ & & $\checkmark$ & $\checkmark$ \\
\hline Crocosphaera watsonii WH 8501 & $\checkmark$ & & $\checkmark$ & $\checkmark$ & $\checkmark$ & & $\checkmark$ & $\checkmark$ \\
\hline Cyanothece sp. PCC 8802 & $\checkmark$ & & $\checkmark$ & $\checkmark$ & $\checkmark$ & & $\checkmark$ & $\checkmark$ \\
\hline Cyanothece sp. PCC 8801 & $\checkmark$ & & $\checkmark$ & $\checkmark$ & $\checkmark$ & & $\sqrt{4}$ & $\sqrt{ }$ \\
\hline Synechocystis sp. PCC 6803 & $\checkmark$ & & $\checkmark$ & $\checkmark$ & $\sqrt{ }$ & $\checkmark$ & & \\
\hline Pleurocapsa sp. PCC 7327 & $\checkmark$ & & $\checkmark$ & $\checkmark$ & $\checkmark$ & & $\checkmark$ & $\checkmark$ \\
\hline Microcystis aeruginosa NIES-843 & $\checkmark$ & & $\checkmark$ & $\checkmark$ & $\checkmark$ & $\checkmark$ & $\checkmark$ & $\checkmark$ \\
\hline Microcystis aeruginosa PCC 7806 & $\checkmark$ & & $\checkmark$ & $\checkmark$ & $\checkmark$ & $\checkmark$ & $\checkmark$ & $\checkmark$ \\
\hline Cyanothece sp. PCC 7822 & $\checkmark$ & $\checkmark$ & $\checkmark$ & $\checkmark$ & $\checkmark$ & $\checkmark$ & $\checkmark$ & $\checkmark$ \\
\hline Cyanothece sp. PCC 7424 & $\checkmark$ & $\checkmark$ & $\checkmark$ & $\checkmark$ & $\checkmark$ & $\checkmark$ & $\checkmark$ & $\checkmark$ \\
\hline \multicolumn{9}{|l|}{ Prochloron didemni P1 } \\
\hline Gloeocapsa sp. PCC 73106 & $\checkmark$ & & $\checkmark$ & $\checkmark$ & $\checkmark$ & $\checkmark$ & $\checkmark$ & $\checkmark$ \\
\hline Synechococcus sp. PCC 7002 & $\checkmark$ & & $\checkmark$ & $\checkmark$ & $\checkmark$ & & & \\
\hline Leptolyngbya sp. PCC 7376 & $\checkmark$ & & $\checkmark$ & $\checkmark$ & $\checkmark$ & & $\checkmark$ & \\
\hline Cyanobacterium stanieri PCC 7202 & $\checkmark$ & & $\checkmark$ & $\checkmark$ & $\checkmark$ & & & \\
\hline Geminocystis herdmani PCC 6308 & $\checkmark$ & & $\checkmark$ & 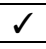 & $\checkmark$ & 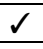 & & \\
\hline Cyanobacterium aponinum sp. PCC 10605 & $\checkmark$ & & $\checkmark$ & $\checkmark$ & $\checkmark$ & 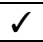 & & \\
\hline Stanieria cyanosphaera PCC 7437 & $\checkmark \dagger$ & $\checkmark$ & $\checkmark$ & $\checkmark$ & $\checkmark$ & $\checkmark$ & $\checkmark$ & $\checkmark$ \\
\hline Pleurocapsa sp. PCC 7319 & $\checkmark$ & & $\checkmark$ & 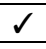 & $\checkmark$ & 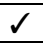 & $\checkmark$ & $\checkmark$ \\
\hline Xenococcus sp. PCC 7305 & $\checkmark$ & & $\checkmark$ & $\checkmark$ & $\checkmark$ & & $\checkmark$ & $\checkmark$ \\
\hline Chroococcidiopsis sp. PCC 6712 & $\checkmark$ & $\checkmark \sqrt{9}$ & $\checkmark$ & $\checkmark$ & $\checkmark$ & $\checkmark$ & $\checkmark$ & $\checkmark$ \\
\hline \multicolumn{9}{|l|}{ Clade B3 } \\
\hline Moorea producens $3 \mathrm{~L}$ & $\checkmark$ & & $\checkmark$ & $\checkmark$ & $\checkmark$ & & $\checkmark$ & $\checkmark$ \\
\hline Coleofasciculus chthonoplastes PCC 7420 & $\checkmark$ & & $\checkmark$ & $\checkmark$ & $\checkmark$ & & & \\
\hline Microcoleus sp. PCC 7113 & $\checkmark$ & $\checkmark 9$ & $\checkmark$ & $\checkmark$ & $\checkmark$ & $\checkmark$ & $\checkmark$ & $\checkmark$ \\
\hline \multicolumn{9}{|l|}{ Other clade B } \\
\hline Crinalium epipsammum PCC 9333 & $\checkmark$ & $\checkmark$ & $\checkmark$ & $\checkmark$ & $\checkmark$ & $\checkmark$ & & $\checkmark$ \\
\hline Chamaesiphon minutus PCC 6605 & $\checkmark$ & & $\checkmark$ & $\checkmark$ & $\checkmark$ & & $\checkmark$ & $\checkmark$ \\
\hline Geitlerinema sp. PCC 7105 & $\checkmark \dagger$ & & $\checkmark$ & $\checkmark$ & $\checkmark$ & & & \\
\hline \multicolumn{9}{|l|}{ Clade C1 } \\
\hline \multicolumn{9}{|l|}{ Synechococcus sp. RCC307 } \\
\hline Prochlorococcus marinus NATL 2A & & & & & & & $\checkmark$ & $\checkmark$ \\
\hline Prochlorococcus marinus NATL 1A & & & & & & & 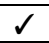 & $\sqrt{ }$ \\
\hline \multicolumn{9}{|l|}{ Prochlorococcus marinus CCMP1986 } \\
\hline Prochlorococcus marinus MIT9515 & & & & & & & $\checkmark$ & $\checkmark$ \\
\hline \multicolumn{9}{|l|}{ Prochlorococcus marinus AS9601 } \\
\hline \multicolumn{9}{|l|}{ Prochlorococcus marinus MIT9301 } \\
\hline \multicolumn{9}{|l|}{ Prochlorococcus marinus MIT9215 } \\
\hline \multicolumn{9}{|l|}{ Prochlorococcus marinus MIT9202 } \\
\hline Prochlorococcus marinus MIT9312 & & & & & & & $\checkmark$ & $\checkmark$ \\
\hline Prochlorococcus marinus MIT9211 & & & & & & & $\checkmark$ & $\sqrt{ }$ \\
\hline Prochlorococcus marinus CCMP1375 & & & & & & & $\checkmark$ & $\sqrt{ }$ \\
\hline Prochlorococcus marinus MIT9313 & & & & & & & $\checkmark$ & $\checkmark$ \\
\hline Prochlorococcus marinus MIT9303 & & & & & & & $\checkmark$ & $\checkmark$ \\
\hline Synechococcus sp. WH8102 & & & & & & & $\checkmark$ & $\checkmark$ \\
\hline Synechococcus sp. CC9605 & & & & & & & $\sqrt{ }$ & $\sqrt{ }$ \\
\hline Synechococcus sp. WH8109 & & & & & & & $\checkmark$ & $\checkmark$ \\
\hline Synechococcus sp. BL107 & & & & & & & $\checkmark$ & $\checkmark$ \\
\hline Synechococcus sp. CC9902 & & & & & & & $\checkmark$ & $\checkmark$ \\
\hline Synechococcus sp. WH7805 & & & & & & & $\checkmark$ & $\checkmark$ \\
\hline Synechococcus sp. WH7803 & & & & & & & $\checkmark$ & $\checkmark$ \\
\hline Synechococcus sp. CC9311 & & & & & & & $\checkmark$ & $\checkmark$ \\
\hline Synechococcus sp. WH8016 & & & & & & & $\checkmark$ & $\checkmark$ \\
\hline Synechococcus sp. RS9916 & & & & & & & $\checkmark$ & $\checkmark$ \\
\hline Synechococcus sp. RS9917 & & & & & & & $\checkmark$ & $\checkmark$ \\
\hline Synechococcus sp. WH5701 & & & & & & & $\checkmark$ & $\sqrt{ }$ \\
\hline Synechococcus sp. CB0205 & & & & & & & $\checkmark$ & $\checkmark$ \\
\hline \multicolumn{9}{|l|}{ Synechococcus sp. CB0101 } \\
\hline Cyanobium gracile PCC 6307 & & & & & & & $\checkmark$ & $\checkmark$ \\
\hline Cyanobium sp. PCC 7001 & & & & & & & $\checkmark$ & $\checkmark$ \\
\hline
\end{tabular}




\begin{tabular}{|c|c|c|c|c|c|c|c|c|}
\hline \multicolumn{9}{|l|}{ Clade C } \\
\hline Prochlorothrix hollandica PCC 9006 & $\checkmark$ & & $\checkmark$ & $\checkmark$ & $\checkmark$ & & $\checkmark$ & $\checkmark$ \\
\hline \multicolumn{9}{|l|}{ Clade C2 } \\
\hline Synechococcus elongatus PCC 7942 & & & & & & & $\checkmark$ & $\checkmark$ \\
\hline Synechococcus elongatus PCC 6301 & & & & & & & $\checkmark$ & $\checkmark$ \\
\hline \multicolumn{9}{|l|}{ Clade C3 } \\
\hline Leptolyngbya sp. PCC 6406 & & & & & & & $\checkmark$ & $\checkmark$ \\
\hline Nodosilinea nodulosa PCC 7104 & $\checkmark \dagger$ & & $\checkmark$ & $\sqrt{ }$ & $\sqrt{ }$ & $\checkmark$ & $\checkmark$ & $\sqrt{ }$ \\
\hline Synechococcus sp PCC 7335 & $\checkmark$ & & $\checkmark$ & $\checkmark$ & $\sqrt{ }$ & & $\checkmark$ & $\sqrt{ }$ \\
\hline Leptolyngbya sp. PCC 7375 & $\checkmark$ & & $\checkmark$ & $\sqrt{ }$ & $\sqrt{ }$ & & $\checkmark$ & $\checkmark$ \\
\hline \multicolumn{9}{|l|}{ Clade D } \\
\hline Geitlerinema sp. PCC 7407 & $\checkmark$ & & $\checkmark$ & $\checkmark$ & $\checkmark$ & & $\checkmark$ & $\sqrt{ }$ \\
\hline Leptolyngbya sp. PCC 6306 & $\checkmark$ & $\checkmark 9$ & $\checkmark$ & $\sqrt{ }$ & $\sqrt{ }$ & $\checkmark$ & & \\
\hline \multicolumn{9}{|l|}{ Clade E } \\
\hline Thermosynechococcus elongatus BP-1 & $\checkmark$ & & $\checkmark$ & $\checkmark$ & $\checkmark$ & & & \\
\hline Synechococcus sp. PCC 6312 & $\sqrt{ }$ & & $\checkmark$ & $\sqrt{ }$ & $\sqrt{ }$ & $\checkmark$ & $\checkmark$ & $\checkmark$ \\
\hline Cyanothece sp. PCC 7425 & $\checkmark$ & $\checkmark$ & $\checkmark$ & $\checkmark$ & $\checkmark$ & & $\checkmark$ & $\checkmark$ \\
\hline Acaryochloris marina MBIC11017 & & & & & $\checkmark$ & & $\checkmark$ & $\checkmark$ \\
\hline Acaryochloris sp. CCMEE5410 & & & & & & & $\checkmark$ & $\checkmark$ \\
\hline \multicolumn{9}{|l|}{ Clade F } \\
\hline Synechococcus sp. PCC 7502 & $\checkmark \dagger$ & & $\checkmark$ & $\checkmark$ & $\checkmark$ & & $\checkmark$ & $\checkmark$ \\
\hline Pseudanabaena sp. PCC 6802 & $\checkmark \dagger$ & & $\checkmark$ & $\sqrt{ }$ & $\sqrt{ }$ & & $\checkmark$ & $\checkmark$ \\
\hline Pseudanabaena sp. PCC 7429 & $\checkmark \dagger$ & & $\checkmark$ & $\checkmark$ & $\sqrt{ }$ & & $\checkmark$ & $\checkmark$ \\
\hline Pseudanabaena sp. PCC 7367 & s† & & $\checkmark$ & $\sqrt{ }$ & $\sqrt{ }$ & $\checkmark$ & $\checkmark$ & $\checkmark$ \\
\hline \multicolumn{9}{|l|}{ Clade G } \\
\hline Synechococcus sp. JA-3-3AB & & & & & & & $\checkmark$ & $\checkmark$ \\
\hline Synechococcus sp. JA-2-3B'a(2-13) & $\checkmark \dagger$ & $\checkmark$ & $\checkmark$ & $\sqrt{ }$ & $\sqrt{ }$ & & $\checkmark$ & $\checkmark$ \\
\hline Synechococcus sp. PCC 7336 & & & & $\checkmark$ & $\checkmark$ & $\checkmark$ & $\checkmark$ & $\checkmark$ \\
\hline \multicolumn{9}{|l|}{ Deeply divergent } \\
\hline Gloeobacter violaceus PCC 7421 & $\checkmark \dagger$ & & $\checkmark$ & $\checkmark$ & $\sqrt{ }$ & & & \\
\hline \multicolumn{9}{|l|}{ Recently discovered } \\
\hline Gloeomargarita lithophora D10 & $\checkmark$ & & $\checkmark$ & $\checkmark$ & $\checkmark$ & & & \\
\hline Gloeobacter kilauensis JS1 & $\checkmark \dagger$ & & $\checkmark$ & $\sqrt{ }$ & $\sqrt{ }$ & & & \\
\hline Richelia intracellularis $\mathrm{HH} 01$ & $\sqrt{2}$ & & $\checkmark$ & & & & $\checkmark$ & $\sqrt{ }$ \\
\hline
\end{tabular}

